\title{
Cochrane
Library
}

Cochrane Database of Systematic Reviews

\section{Surgical interventions (microfracture, drilling, mosaicplasty, and allograft transplantation) for treating isolated cartilage defects of the knee in adults (Review)}

Gracitelli GC, Moraes VY, Franciozi CES, Luzo MV, Belloti JC

Gracitelli GC, Moraes VY, Franciozi CES, Luzo MV, Belloti JC.

Surgical interventions (microfracture, drilling, mosaicplasty, and allograft transplantation) for treating isolated cartilage defects of the knee in adults.

Cochrane Database of Systematic Reviews 2016, Issue 9. Art. No.: CD010675.

DOI: 10.1002/14651858.CD010675.pub2.

www.cochranelibrary.com

Surgical interventions (microfracture, drilling, mosaicplasty, and allograft transplantation) for treating isolated cartilage defects of the knee in adults (Review) 
TABLE OF CONTENTS

HEADER

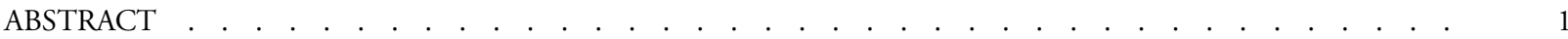

PLAIN LANGUAGE SUMMARY . . . . . . . . . . . . . . . . . . . . . . . . . . . . . . . . .

SUMMARY OF FINDINGS FOR THE MAIN COMPARISON . . . . . . . . . . . . . . . . . . . . . . . 4 . 4

BACKGROUND . . . . . . . . . . . . . . . . . . . . . . . . . . . . . . . . . . . . . . . . . . . 8

OBJECTIVES . . . . . . . . . . . . . . . . . . . . . . . . . . . . . . . . . . . . . . . . . . . . . . . . . . .

METHODS . . . . . . . . . . . . . . . . . . . . . . . . . . . . . . . . . . . . . .

RESUlTS . . . . . . . . . . . . . . . . . . . . . . . . . . . . . . . . . . . . 12

Figure 1. . . . . . . . . . . . . . . . . . . . . . . . . . . . . . . . . . . . . 12

Figure 2. . . . . . . . . . . . . . . . . . . . . . . . . . . . . . . . . . . . . . 15

DISCUSSION . . . . . . . . . . . . . . . . . . . . . . . . . . . . . . . . . . . . . . . 18

AUTHORS' CONCLUSIONS . . . . . . . . . . . . . . . . . . . . . . . . . . . . . . . . . . . . . .

ACKNOWLEDGEMENTS . . . . . . . . . . . . . . . . . . . . . . . . . . . . . . . . . . . . . . .

REFERENCES . . . . . . . . . . . . . . . . . . . . . . . . . . . . . . . . . . . . . . 21

CHARACTERISTICS OF STUDIES . . . . . . . . . . . . . . . . . . . . . . . . . . . . . . . . . . . . . .

DATA AND ANALYSES . . . . . . . . . . . . . . . . . . . . . . . . . . . . . . . . . . . 33

Analysis 1.1. Comparison 1 Mosaicplasty versus microfracture, Outcome 1 Function (all scores/instruments): intermediate term (1 to 5 years of follow-up).

Analysis 1.2. Comparison 1 Mosaicplasty versus microfracture, Outcome 2 Function (all scores/instruments): long term (5 or more years of follow-up). . . . . . . . . . . . . . . . . . . . . . . . . . . . . . . . . . . . . . . . .

Analysis 1.3. Comparison 1 Mosaicplasty versus microfracture, Outcome 3 Quality of life: long-term (5 or more years of follow-up).

Analysis 1.4. Comparison 1 Mosaicplasty versus microfracture, Outcome 4 Failure of treatment and adverse effects: longterm ( 5 or more years of follow-up).

Analysis 1.5. Comparison 1 Mosaicplasty versus microfracture, Outcome 5 Pain: long-term (5 or more years of followup).

Analysis 1.6. Comparison 1 Mosaicplasty versus microfracture, Outcome 6 Activity (Tegner score; 1 to 10: best score): intermediate term (1 to 5 years follow-up).

Analysis 1.7. Comparison 1 Mosaicplasty versus microfracture, Outcome 7 Activity (Tegner score; 1 to 10: best score): long term $(5$ or more years follow-up). . . . . . . . . . . . . . . . . . . . . . . . . . . . . . . . . . . . . . 38

Analysis 1.8. Comparison 1 Mosaicplasty versus microfracture, Outcome 8 Sports activity. . . . . . . . . . . . 39

Analysis 1.9. Comparison 1 Mosaicplasty versus microfracture, Outcome 9 Quality of cartilage at long-term follow-up: magnetic resonance image (satisfactory cartilage characteristics).

Analysis 1.10. Comparison 1 Mosaicplasty versus microfracture, Outcome 10 Quality of cartilage: "Second-look" arthroscopy at around 1 year. Excellent and good. . . . . . . . . . . . . . . . . . . . . . . .

Analysis 1.11. Comparison 1 Mosaicplasty versus microfracture, Outcome 11 Quality of cartilage: presence of hyaline cartilage in biopsy.

Analysis 1.12. Comparison 1 Mosaicplasty versus microfracture, Outcome 12 Quality of cartilage at long term follow-up: signs of radiographic osteoarthritis. . . . . . . . . . . . . . . . . . . . . . . . . . . . . . . . . . . . . . 4242

ADDITIONAL TABLES . . . . . . . . . . . . . . . . . . . . . . . . . . . . . . . . . . 42

APPENDICES . . . . . . . . . . . . . . . . . . . . . . . . . . . . . . . . . . . . . . . . . . 44

CONTRIBUTIONS OF AUTHORS . . . . . . . . . . . . . . . . . . . . . . . . . . . . . . . . . . . . . . . . . . . . . .

DECLARATIONS OF INTEREST . . . . . . . . . . . . . . . . . . . . . . . . . . . . . . . . . . . . . . . . . $\quad . \quad 47$

SOURCES OF SUPPORT . . . . . . . . . . . . . . . . . . . . . . . . . . . . . . . . . . . . . . . . 47

DIFFERENCES BETWEEN PROTOCOL AND REVIEW . . . . . . . . . . . . . . . . . . . . . . . . . 47

Surgical interventions (microfracture, drilling, mosaicplasty, and allograft transplantation) for treating isolated cartilage defects of the knee in adults (Review)

Copyright $\odot 2016$ The Cochrane Collaboration. Published by John Wiley \& Sons, Ltd. 


\title{
Surgical interventions (microfracture, drilling, mosaicplasty, and allograft transplantation) for treating isolated cartilage defects of the knee in adults
}

\author{
Guilherme C Gracitelli ${ }^{1}$, Vinícius Y Moraes ${ }^{1}$, Carlos ES Franciozi ${ }^{1}$, Marcus V Luzo ${ }^{1}$, João Carlos Belloti ${ }^{1}$ \\ ${ }^{1}$ Department of Orthopaedics and Traumatology, Universidade Federal de São Paulo, São Paulo, Brazil \\ Contact address: Guilherme C Gracitelli, Department of Orthopaedics and Traumatology, Universidade Federal de São Paulo, Rua \\ Borges Lagoa, 778, São Paulo, São Paulo, 040450001, Brazil. ggracitelli@gmail.com. gracitelli@uol.com.br. \\ Editorial group: Cochrane Bone, Joint and Muscle Trauma Group. \\ Publication status and date: New, published in Issue 9, 2016. \\ Review content assessed as up-to-date: 5 February 2016.
}

Citation: Gracitelli GC, Moraes VY, Franciozi CES, Luzo MV, Belloti JC. Surgical interventions (microfracture, drilling, mosaicplasty, and allograft transplantation) for treating isolated cartilage defects of the knee in adults. Cochrane Database of Systematic Reviews 2016, Issue 9. Art. No.: CD010675. DOI: 10.1002/14651858.CD010675.pub2.

Copyright (C) 2016 The Cochrane Collaboration. Published by John Wiley \& Sons, Ltd.

\begin{abstract}
A B S T R A C T
Background

Cartilage defects of the knee are often debilitating and predispose to osteoarthritis. Microfracture, drilling, mosaicplasty, and allograft transplantation are four surgical treatment options that are increasingly performed worldwide. We set out to examine the relative effects of these different methods.

\section{Objectives}

To assess the relative effects (benefits and harms) of different surgical interventions (microfracture, drilling, mosaicplasty, and allograft transplantation) for treating isolated cartilage defects of the knee in adults.

\section{Search methods}

We searched the Cochrane Bone, Joint and Muscle Trauma Group Specialised Register, CENTRAL, EMBASE, MEDLINE, SPORTDiscus, LILACS, trial registers and conference proceedings up to February 2016.

\section{Selection criteria}

Any randomised or quasi-randomised trials that evaluated surgical interventions (microfracture, drilling, mosaicplasty, and allograft transplantation) for treating isolated cartilage defects of the knee in adults.

Data collection and analysis

At least two review authors independently selected studies, assessed risk of bias and extracted data. Intervention effects were assessed using risk ratios (RR) for dichotomous data and mean differences (MD) for continuous data, with 95\% confidence intervals (CI). Data were pooled using the fixed-effect model, where possible.
\end{abstract}

Surgical interventions (microfracture, drilling, mosaicplasty, and allograft transplantation) for treating isolated cartilage defects of the knee in adults (Review)

Copyright $\odot 2016$ The Cochrane Collaboration. Published by John Wiley \& Sons, Ltd. 


\section{Main results}

We included three randomised controlled trials comparing mosaicplasty versus microfracture for isolated cartilage defects in adults. Two trials were single-centre trials and one involved three centres. These small trials reported results for a total of 133 participants, of whom 79 (59\%) were male. Mean participant age in the three trials ranged from 24.4 years to 32.3 years. All studies included grade 3 or 4 cartilage lesions (International Cartilage Repair Society (ICRS) classification). The defect area ranged from $1.0 \mathrm{~cm}^{2}$ to $6.0 \mathrm{~cm}^{2}$; the mean area in all three trials was $2.8 \mathrm{~cm}^{2}$. No trials of allograft transplantation or drilling were identified.

All trials were judged as being at high or unclear risk of performance and reporting bias. We judged that the quality of evidence was very low for all outcomes. For individual outcomes, we downgraded the quality of evidence by one or two levels for risk of bias, one level for indirectness where there were data from a single-centre trial only, one or two levels for imprecision where there were wide confidence intervals and an insufficient number of events, and one level for inconsistency reflecting heterogeneity. This means that we are very uncertain about the estimates for all outcomes.

There is very low quality evidence from one single-centre trial (57 participants), which included athletes only, that mosaicplasty resulted in higher patient-reported function scores (probably the IKDC 2000 subjective knee evaluation score) compared with microfracture (range 0 to 100; higher score = better function) at one year follow-up (MD 10.29 favouring mosaicplasty, 95\% CI 7.87 to 12.71). Very low quality evidence from the same trial showed that this effect persisted in the long term at 10 years follow-up. However, there is very low quality evidence from the two other trials (72 participants) of little difference in patient-reported function, assessed via the Lysholm score (range 0 to 100; higher score = better function), between the two groups at long-term follow-up (MD - 1.10 favouring microfracture, $95 \%$ CI -4.54 to 2.33 ). One trial ( 25 participants) provided very low quality evidence of no significant difference between the two groups in quality of life or pain at long-term follow-up. Pooled results for treatment failure - primarily symptom recurrence reported at long-term follow-up (means ranging from 6.3 to 1.4 years) in the three trials (129 participants) favoured mosaicplasty (10/ 64 versus 20/65; RR $0.47,95 \%$ CI 0.24 to 0.90). Based on an illustrative risk of 379 treatment failures per 1000 patients treated with microfracture, there is very low quality evidence that 201 fewer patients (95\% CI 38 to 288 fewer) would have treatment failure after mosaicplasty. All three trials reported activity scores but due to clear statistical and clinical heterogeneity, we did not pool the long term Tegner score results. There was very low quality evidence from one study (57 participants) of higher Tegner scores - indicating greater activity - at intermediate-term and long-term follow-up in the mosaicplasty group; however, the between-group difference may not be clinically important. The other two trials provided very low quality evidence of no significant difference between the two groups in activity scores.

\section{Authors' conclusions}

We found no evidence from randomised controlled trials on allograft transplantation or drilling. The very low quality evidence from RCTs comparing mosaicplasty with microfracture is insufficient to draw conclusions on the relative effects of these two interventions for treating isolated cartilage defects of the knee in adults. Of note is that treatment failure, with recurrence of symptoms, occurred with both procedures. Further research is needed to define the best surgical option for treating isolated cartilage defects. We suggest the greatest need is for multi-centre RCTs comparing reconstructive procedures (mosaicplasty versus allograft transplantation) for large osteochondral lesions and reparative procedures (microfracture versus drilling) for small chondral lesions.

\section{PLAIN LANGUAGE S UMMAY}

\section{Surgical treatment options (microfracture, drilling, mosaicplasty, and allograft transplantation) for cartilage injuries of the} knee in adults

\section{What is the medical problem?}

The layer of cartilage covering the knee joint surfaces helps protect the joint and reduce friction during movement. Cartilage injuries of the knee in adults can result from trauma, such as during sport, or from a cartilage disease (osteochondritis). If left untreated, cartilage injuries do not mend by themselves and can lead to significant destruction of the joint (osteoarthritis).

\section{What treatments are available?}

A number of treatment options are available for cartilage injuries but are often aimed at treating symptoms such as pain rather than providing a cure. Non-surgical methods, such as physical therapy, may relieve symptoms but cannot heal cartilage injuries. Microfracture, drilling, mosaicplasty, and allograft transplantation are increasingly available surgical treatments that attempt to preserve the joint.

Surgical interventions (microfracture, drilling, mosaicplasty, and allograft transplantation) for treating isolated cartilage defects of the 


\section{What are microfracture, drilling, mosaicplasty, and allograft transplantation?}

Microfracture and drilling are minimally invasive surgeries (key hole surgery) that promote bleeding from the bone to create a clot in the cartilage defect. This can then form a tissue similar to cartilage. Mosaicplasty is an osteochondral transplant in which tissue is harvested from a less-demanding area of the knee to cover a cartilage defect in a more important area. Allograft transplantation treatment uses tissue harvested from fresh cadavers to cover only the injured area.

\section{Which of these surgical techniques works better in practice?}

This review examines the evidence from randomised controlled trials that compared two or more of these surgical methods in clinical practice.

We searched a number of medical databases up to February 2016 and found three studies that compared mosaicplasty versus microfracture. These studies reported results for a total of 133 participants, the majority of whom were young adults and male. No trials of allograft transplantation or drilling were identified.

One study conducted at a single centre found better patient-reported function after mosaicplasty at 1, 2, 3, and 10 years follow-up. However, the other studies did not find a difference in function (two studies), pain (one study) or activities of daily living (one study) between mosaicplasty and microfracture in the long term (6 to 10 years follow-up). Treatment failure, with recurrence of symptoms, occurred with both procedures. Data pooled from the three trials showed half as many people had treatment failure in the mosaicplasty group. However, more evidence is required to test whether this is a true finding. The evidence regarding activity levels in the long term was inconclusive.

We considered that all the evidence for these outcomes was very low quality. This means that we are unsure of these results, which are likely to change when more evidence becomes available.

\section{Conclusions}

The currently available evidence is not enough to conclude whether mosaicplasty or microfracture is better for treating isolated cartilage defects of the knee in adults. Treatment failure occurred with both methods. Further research is needed to define the best surgical option for treating isolated cartilage defects. 
SUMMARY OF FINDINGS FOR THE MAIN COMPARISON [Explanation]

Mosaicplasty compared with microfracture for adults with isolated cartilage defects of the knee

Patient or population: Adults with isolated cartilage defects (defect areas $1.0 \mathrm{~cm}^{2}$ to $6.0 \mathrm{~cm}^{2}$ ) of the knee Settings: Hospital

Intervention: Mosaicplasty (arthroscopic in two trials: defect area $1.0 \mathrm{~cm}^{2}$ to $4.0 \mathrm{~cm}^{2}$; mini-invasive arthrotomy in one trial: defect area $2.0 \mathrm{~cm}{ }^{2}$ to $6.0 \mathrm{~cm}{ }^{2}$ )

Comparison: Microfracture (all arthroscopic)

\begin{tabular}{|c|c|c|c|c|c|c|}
\hline \multirow[t]{3}{*}{ Outcomes } & \multicolumn{2}{|c|}{ Illustrative comparative risks* $(95 \% \mathrm{Cl})$} & \multirow{3}{*}{$\begin{array}{l}\text { Relative effect } \\
(95 \% \mathrm{Cl})\end{array}$} & \multirow{3}{*}{$\begin{array}{l}\text { Number of participants } \\
\text { (studies) }\end{array}$} & \multirow{3}{*}{$\begin{array}{l}\text { Quality of the evidence } \\
\text { (GRADE) }\end{array}$} & \multirow[t]{3}{*}{ Comments } \\
\hline & Assumed risk & Corresponding risk & & & & \\
\hline & Microfracture & Mosaicplasty & & & & \\
\hline $\begin{array}{l}\text { Function (all scores/in- } \\
\text { struments): intermedi- } \\
\text { ate term } \\
\text { IKDC } 2000 \text { (version) } \\
\text { score. Scale from: } 0 \text { to } \\
\text { 100; higher scores = } \\
\text { better function. } \\
\text { Follow-up: } 1 \text { year }\end{array}$ & $\begin{array}{l}\text { The mean function } \\
\text { (IKDC score): interme- } \\
\text { diate term in the mi- } \\
\text { crofracture group was } \\
\mathbf{7 5 . 5 9} \text { points }\end{array}$ & $\begin{array}{l}\text { The mean function } \\
\text { (IKDC score): interme- } \\
\text { diate term in the mo- } \\
\text { saicplasty group was } \\
10.29 \text { higher } \\
\text { ( } 7.87 \text { to } 12.71 \text { higher) }\end{array}$ & $\begin{array}{l}\text { MD } 10.29(7.87 \text { to } 12 . \\
71)\end{array}$ & $\begin{array}{l}57 \\
\text { (1 study) }\end{array}$ & $\begin{array}{l}\oplus \bigcirc \bigcirc \bigcirc \\
\text { very low }\end{array}$ & $\begin{array}{l}\text { This single- } \\
\text { centre study included } \\
\text { athletes only. The clini- } \\
\text { cal importance of a } 10 \\
\text { point difference in IKDC } \\
\text { scores has not been es- } \\
\text { tablished. The trial re- } \\
\text { ports referred to these } \\
\text { as "ICRS scores" }\end{array}$ \\
\hline $\begin{array}{l}\text { Function (all scores/in- } \\
\text { struments): long term } \\
\text { Scale from: } 0 \text { to } 100 ; \\
\text { higher scores = better } \\
\text { function. } \\
\text { Follow-up: } 5 \text { or more } \\
\text { years }\end{array}$ & $\begin{array}{l}\text { The mean function } \\
\text { (Lysholm score) ranged } \\
\text { across microfracture } \\
\text { groups from } \\
69.7 \text { to } 85.6 \text { points }\end{array}$ & $\begin{array}{l}\text { The mean function } \\
\text { (Lysholm score): long } \\
\text { term in the mosaic- } \\
\text { plasty groups was } \\
1.1 \text { lower } \\
\text { (4.54 lower to } 2.33 \\
\text { higher) }\end{array}$ & MD $-1.10(-4.54$ to 2.33$)$ & $\begin{array}{l}72 \\
\text { (2 studies) }\end{array}$ & $\begin{array}{l}\oplus \bigcirc \bigcirc \bigcirc \\
\text { very low }\end{array}$ & $\begin{array}{l}\text { Three studies ex- } \\
\text { pressed function as ei- } \\
\text { ther Lysholm or ICRS } \\
\text { scores. However, the } \\
\text { studies were not pooled } \\
\text { because of substantial } \\
\text { heterogeneity } \\
\text { It is unlikely that the } \\
95 \% \mathrm{Cl} \text { for the Lysholm } \\
\text { scores includes a clin- } \\
\text { ically important dif- }\end{array}$ \\
\hline
\end{tabular}




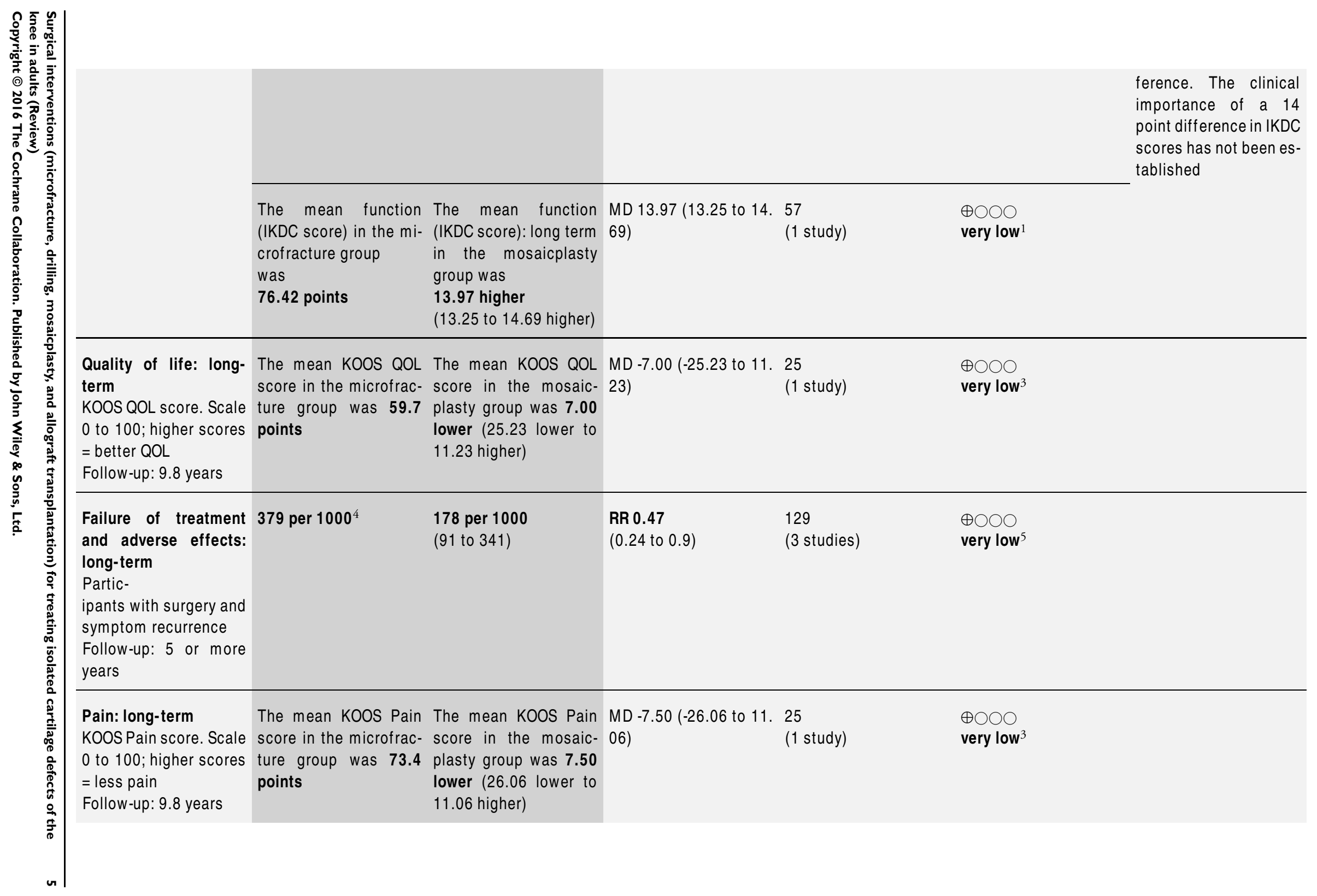


Activity: intermediate The mean activity: in- The mean activity: in- MD $0.48(0.21$ to 0.75$) 57$

term ( 1 to 5 years fol- termediate term ( 1 to termediate term ( 1 to

low-up) 5 years follow-up) in 5 years follow-up) in

(1 study)

$\oplus \bigcirc \bigcirc \bigcirc$

Tegner Score. Scale the microfracture group the mosaicplasty group

from: 0 to 10; higher was

was

scores $=$ better activity. $\mathbf{6 . 8 8}$ points

0.48 higher

Follow-up: mean 3

(0.21 to 0.75 higher)

years

Activity: long term (5 The mean activity: long The mean activity: Iong Results from 3 trials: 25

or more years follow- term ( 5 or more years term ( 5 or more years MD -1.04 (-2.56 to 0.48 ) (1 study)

up)

follow-up) in the three follow-up) in the three;

47

$\oplus \bigcirc \bigcirc \bigcirc$

Tegner Score. Scale microfracture groups mosaicplasty groups MD $0.20(-0.57$ to 0.97$)$ (1 study)

from: 0 to 10; higher was 4.18,5.1, and 6.14 was

scores $=$ better activity. points

1.04 lower

MD 0.72 (0.46 to 0.98) (1 study)

very low

Follow-up: mean 6.3 to

(2.56 lower to 0.48

10.4 years

higher);

0.20 higher

(0.57 lower to 0.97

higher);

0.72 higher

(0.46 higher to 0.98

higher)

*The basis for the assumed risk (e.g. the median control group risk across studies) is provided in footnotes. The corresponding risk (and its $95 \% \mathrm{Cl}$ ) is based on the assumed risk in the comparison group and the relative effect of the intervention (and its $95 \% \mathrm{Cl}$ ).

Cl: confidence interval; ICRS: International Cartilage Repair Society; IKDC: International Knee Documentation Committee; KOOS: Knee Injury and Osteoarthritis Outcome Score; MD: mean difference; QOL: quality of life; RR: risk ratio

GRADE Working Group grades of evidence

High quality: Further research is very unlikely to change our confidence in the estimate of effect.

Moderate quality: Further research is likely to have an important impact on our confidence in the estimate of effect and may change the estimate.

Low quality: Further research is very likely to have an important impact on our confidence in the estimate of effect and is likely to change the estimate.

Very low quality: We are very uncertain about the estimate.

${ }^{1}$ Downgraded three levels: one level for serious limitations due to risk of bias (insufficient information about sequence generation and allocation concealment, lack of blinding of surgeons, possible selective reporting); one level for indirectness 
(single centre trial; athletes only); one level for serious inconsistency due to substantial variation in effect estimate and $95 \% \mathrm{Cl}$ when considered alongside other studies reporting long term follow-up data on similar outcome.

2 Downgraded three levels: two levels for very serious limitations due to high risk of bias (including lack of allocation concealment, lack of blinding of outcome assessment, selective reporting bias); one level for serious imprecision due to small sample size $(n=72)$; and one level for serious inconsistency due to substantial variation in effect estimate and $95 \% \mathrm{Cl}$ across all studies reporting long term follow-up data.

${ }^{3}$ Downgraded three levels: two levels for very serious limitations due to high risk of bias (especially lack of allocation concealment) and two levels for very serious imprecision: wide confidence interval and contributions from only 25 participants of one trial.

${ }^{4}$ Assumed risk for microfracture was based on the median control group risk across studies.

5 Downgraded three levels: two levels for very serious limitations due to high risk of bias (including lack of allocation concealment, lack of blinding of outcome assessment, selective reporting bias); and one level for serious imprecision due to low number of events (30)

${ }^{6}$ Downgraded three levels: very serious limitations due to risk of bias (insufficient information about sequence generation and allocation concealment; lack of blinding of patients, personnel, and outcome assessors); serious inconsistency due to substantial variation in effect estimate (pooled data: $I^{2}=68.2 \%$ ) 


\section{B A C K G R O U N D}

\section{Description of the condition}

Hyaline articular cartilage is a specialised tissue present in synovial joints, such as the knee. It functions as a low-friction articulating surface allowing joint motion and loading. Hyaline cartilage is composed of collagen, noncollagenous proteins, water, and chondrocytes (cells). Cartilage is avascular and aneural, deriving nutrition from synovial fluid through diffusion and from the subchondral bone (Buckwalter 1990; Buckwalter 1992). Hyaline cartilage has a poor repair capacity due to poor vascularity, the inability of chondrocytes to multiply, and the low concentration of chondrocytes in the cartilage tissue. Therefore, injury or damage to cartilage tissue can lead to significant detrimental consequences for the joint and the individual.

Cartilage injuries affect people of all ages. It is estimated that 900,000 people per year develop cartilage disease in the United States alone (Mithoefer 2009). The prevalence in the population who are athletes is $36 \%$ higher than in the normal population (Flanigan 2010). Cartilage injuries are detected in up to $60 \%$ of knee arthroscopies (Widuchowski 2007). The natural history of a knee with cartilage injury is poorly understood but evidence suggests that progression of cartilage injury to frank osteoarthritis is common (Davies-Tuck 2008).

Cartilage injuries are commonly associated with symptoms such as pain, joint locking, articular effusion, and crepitus (Brittberg 1994). Diagnosis can be made by magnetic resonance imaging (MRI) and arthroscopy. Knee cartilage lesions represent a potential threat to joint viability.

\section{Description of the intervention}

Several treatment methods for chondral injuries of the knee are cited in the literature. Conservative treatment manages to achieve symptom relief in some low-demand patients. Current surgical treatment options for symptomatic patients include reparative and reconstructive procedures. Reparative procedures involve techniques that aim to stimulate patients' cells to form hyaline cartilage-like tissue; a period of tissue maturation is expected. Reconstructive procedures involve techniques that transplant autografts or allografts with mature hyaline cartilage with the subchondral bone attached. Bone consolidation is expected and no graft maturation is necessary.

Reparative procedures for knee cartilage injury include microfracture (MF), abrasion arthroplasty, drilling, and 'biological procedures' involving cell culture (Johnson 2001; Lijoi 2001; Mithoefer 2006; Pridie 1959; Strauss 2009). The primary goal of MF and abrasion arthroplasty is to promote bleeding from the subchondral bone to create a blood clot at the lesion site, which then may differentiate into fibrocartilage tissue. The microfracture technique involves the use of an arthroscopic awl that is advanced manually to make holes in the subchondral bone with depths of $2 \mathrm{~mm}$ to $4 \mathrm{~mm}$ and separated $3 \mathrm{~mm}$ to $4 \mathrm{~mm}$ apart. The drilling technique uses the same principal, instead with motorized drills to make holes in the subchondral plate. The arthroscopic awls seem to not produce thermal necrosis of the bone compared with motorized drills; this could influence the bleeding needed for the subchondral bone and clot formation. The abrasion arthroplasty technique is based on the removal of a superficial layer of subchondral bone, $1 \mathrm{~mm}$ to $3 \mathrm{~mm}$ thick, with motorized instruments to expose interosseous vessels for possible fibrocartilage formation. Although fibrocartilage tissue has different biological, structural, and mechanical properties compared with the originally intact hyaline cartilage (Kaul 2012), clinical improvement is nonetheless observed in many patients (Gobbi 2005; Kreuz 2006; Mithoefer 2009; Steadman 2003).

Biological procedures are modern reparative procedures based on the advancements of regenerative medicine, represented by different generations of autologous chondrocyte implantation (ACI). Chondrocyte implantation is a two-stage procedure. The first stage consists of harvesting cartilage tissue during arthroscopy, which is then processed in the laboratory to aseptically isolate chondrocytes and expand their numbers under closely-regulated cell culture conditions. The second stage involves surgical implantation of the chondrocytes into the knee under a periosteal patch (Brittberg 1994; Mithofer 2005; Peterson 2010). Second-generation ACI techniques introduced cell carriers for cell stabilisation (Bartlett 2005), and third-generation approaches employ threedimensional biocompatible scaffolds to house the transplanted chondrocytes (Marcacci 2005). These techniques, many of which remain in early developmental stages and require further research before they can be applied clinically, are not covered in this review (Bonzani 2006; Nukavarapu 2013; Vasiliadis 2010b).

Reconstructive procedures available for treating knee cartilage injuries are mosaicplasty (osteochondral autograft transplantation) and allograft transplantation. These are implantations of wellformed osteochondral tissue (unit of osteochondral plugs or constructs), and no regeneration of cartilage is necessary (Ghazavi 2007; Gracitelli 2015; Hangody 1998).

Mosaicplasty, or osteochondral autograft transplantation, involves excising round plugs of cartilage and underlying bone from nonweight bearing areas of the femur, such as the intercondylar notch, medial trochlea, and the lateral trochlea near the sulcus terminalis, for transplantation; plugs for transplantation are usually taken from the injured knee but can be harvested from the contralateral knee if the injured area is particularly extensive (Hangody 1998). Usually, several round plugs are necessary which, when inserted into drilled holes of the injured knee joint surface, form a mosaic pattern. The space between the plugs ultimately fills with newlyformed fibrocartilage (Hangody 2008; Solheim 2010).

Allograft transplantation is another type of transplant using fresh osteochondral plugs taken from cadaveric donors. The primary advantage is there is no restriction on the size or number of plugs that can be harvested from the donor knee, both of which are 
limited in autologous mosaicplasty (Bugbee 2012; Gross 1975). Thus, osteochondral allograft plugs are more useful for treating larger chondral or osteochondral lesions with areas larger than 2 $\mathrm{cm}^{2}$ that may occur with trauma, osteonecrosis, and osteochondritis dissecans (Bugbee 2002; Krych 2012). Generally, the donor is screened for viral and bacterial infectious diseases. This delays transplantation by 10 to 14 days, during which time the endogenous chondrocyte viability decreases. However, chondrocyte viability can be preserved for longer times with adequate solutions and temperature control in laboratory studies (Stoker 2012).

\section{How the intervention might work}

The reparative procedures (microfracture and drilling) aim to facilitate the differentiation of primitive mesenchymal stem cells from the subchondral bone into functional fibrocartilage. These techniques are based on different types of stimulation of subchondral bone. Autologous transplant (mosaicplasty) transfers intact osteochondral plugs from non-weight bearing areas of the knee to the lesioned area, aiming to restore cartilage congruity. Allograft transplants use 'fresh' donor samples to regenerate the damaged joint area by reconstructing a functional cartilage surface.

The reparative procedures create fibrocartilage in an attempt to substitute cartilage lesions, but no hyaline cartilage properties are expected. These are easy and reproducible techniques that can be readily performed when arthroscopy is available. Mosaicplasty has the advantage of transferring cartilage and bone plugs with original cartilage properties, but donor site complications and morbidity are additional problems of this method. Allograft transplants have the advantage of no donor site morbidity compared with mosaicplasty but have the disadvantages of potential disease transmission and decreased cell viability.

\section{Why it is important to do this review}

Trauma related cartilage defects of the knee in adults are very common and are considered to greatly increase the risk of degenerative changes leading to knee osteoarthritis. We intend to elucidate and compare the effects of commonly used surgical interventions (microfracture, drilling, mosaicplasty, and allograft transplantation) for treating isolated cartilage defects in adult knees in order to inform clinical practice and future research. Our review did not report on autologous chondrocyte implantation, a technically more challenging and expensive procedure, which is covered in another Cochrane Review (Vasiliadis 2010a).

\section{O B JE C T I VES}

To assess the relative effects (benefits and harms) of different surgical interventions (microfracture, drilling, mosaicplasty, and allo- graft transplantation) for treating isolated cartilage defects of the knee in adults.

\section{METHODS}

\section{Criteria for considering studies for this review}

\section{Types of studies}

We included randomised and quasi-randomised trials (using a method of allocating participants to treatment groups which is not strictly random, for example by patient hospital number) evaluating surgical interventions (microfracture, drilling, mosaicplasty, and allograft transplantation) for treating isolated cartilage defects of the knee.

\section{Types of participants}

We included adults (typically older than 18 years) who were diagnosed and treated for symptomatic, isolated cartilage lesions on the medial or lateral femoral condyle, trochlea, or patella. The indications for surgical treatment were lesions of grades three and four of the International Cartilage Repair Society (ICRS; Brittberg 2003; see Appendix 1). Trials focusing primarily on the treatment of people with multiple cartilage lesions, moderate or severe osteoarthritis, rheumatoid diseases, and osteonecrosis were excluded.

\section{Types of interventions}

We included trials comparing different surgical interventions (microfracture, drilling, mosaicplasty, and allograft transplantation). When presenting the results from different comparisons, we defined the intervention involving the least damage to either the injured area or to donor areas as the control. Thus, in a comparison of mosaicplasty versus microfracture, microfracture was selected as the control intervention.

We did not include trials looking at autologous chondrocyte implantation because this intervention has been covered in another Cochrane Review (Vasiliadis 2010a).

\section{Types of outcome measures}

\section{Primary outcomes}

1. Knee function, as assessed by validated tools such as the Western Ontario and McMaster Universities Arthritis Index (WOMAC; Bellamy 1988), Hospital for Special Surgery Score (HSS; Lukianov 1987), International Knee Documentation Committee Score (IKDC; Irrgang 2001), Lysholm score (Kocher 
2004; Lysholm 1982), Knee Injury and Osteoarthritis Outcome Score (KOOS; Roos 1998).

2. Quality of life measures, as assessed by tools such as the Short Form 36 (Ware 1992), World Health Organization Quality of Life (WHOQOL; Masthoff 2005), EuroQol (EQ5D; EuroQol Group 1990), KOOS Quality of Life subscale (KOOS QOL; Roos 1998).

3. Failure of treatment and adverse effects (infection, revision surgery, arthrofibrosis with stiffness, loosening of fibrocartilage shown in 'second-look' surgery, and donor site morbidity).

\section{Secondary outcomes}

1. Pain, using a visual analogue scale (VAS; Revill 1976) or the KOOS Pain subscale (Roos 1998).

2. Satisfactory outcome, as rated by the patient.

3. Activity level, as assessed by tool such as the Tegner activity level scale (Tegner 1985), ICRS (e.g. activity levels in the Cartilage Injury Standard Evaluation Form-2000), and return to normal daily activities.

4. Signs of quality of cartilage, as assessed by MRI, arthroscopic appearance in 'second-look' surgery, and histologic quality in 'second-look' surgery with biopsy.

\section{Timing of outcome assessment}

Outcome assessment was analysed by short-term (less than one year), intermediate-term (one up to five years), and long-term (more than five years) follow-up.

\section{Search methods for identification of studies}

\section{Electronic searches}

We searched the Cochrane Bone, Joint and Muscle Trauma Group Specialised Register (8 February 2016), the Cochrane Central Register of Controlled Trials (CENTRAL; The Cochrane Library 2016, Issue 2), EMBASE (via Ovid; 1980 to 2016 Week 5), MEDLINE (via Ovid; 1946 to January Week 4 2016), MEDLINE In-Process \& Other Non-Indexed Citations (5 February 2016), SPORTDiscus (via EBSCOhost; 1985 to 5 February 2016), and LILACS: Latin American and Caribbean Health Science Literature (via Bireme IAHx interface; 1982 to 7 March 2016).

In MEDLINE, the Cochrane highly sensitive search strategy for identifying randomised trials (sensitivity-maximizing version; Lefebvre 2011) was combined with the subject-specific search. Search strategies for CENTRAL, MEDLINE, EMBASE, SPORTDiscus, and LILACS can be found in Appendix 2.

We searched the WHO International Clinical Trials Registry Platform (WHO ICTRP), ClinicalTrials.gov, and the ISRCTN registry for recently-concluded trials and for trials under development (07 March 2016).
We did not apply any language restrictions.

\section{Searching other resources}

Our search included reference lists of studies and reviews, and non-scholarly internet sources (websites of relevant medical industry and cartilage specialists). Additionally, we emailed knee surgery researchers and societies for relevant data: the International Cartilage Repair Society; the Anterior Cruciate Ligament Study Group; the Brazilian Society of Knee Surgery; and the International Society of Arthroscopy, Knee Surgery, and Orthopaedic Sports Medicine. We searched the conference abstracts and summaries of the following conferences (2005 to March 2014): ISAKOS (International Society of Arthroscopy, Knee Surgery, and Orthopaedic Sports Medicine); SICOT (Société Internationale de Chirurgie Orthopédique et de Traumatologie); AOSSM (American Orthopaedic Society for Sports Medicine); and AAOS (American Academy of Orthopaedic Surgeons).

\section{Data collection and analysis}

\section{Selection of studies}

Two review authors (GG and VM) independently screened titles and abstracts of the downloaded search results for potentially eligible studies. Where possible, we obtained full reports of studies identified as potentially eligible. The same two authors independently performed final study selection. We resolved any disagreements by discussion or, if necessary, by involving a third author for agreement to be reached (CF or PD). When there was still any doubt about an article, we contacted the trial authors for clarification of study details.

\section{Data extraction and management}

Two review authors (GG and VM) independently extracted data using a data extraction form. We resolved potential author discord through discussion or, when necessary, by involving a third author to establish consensus (CF).

\section{Assessment of risk of bias in included studies}

Two review authors (GG and CF) independently assessed the risk of bias of the included studies using Cochrane's 'Risk of bias' tool (Higgins 2011). We resolved disagreements by consensus between the two authors and, when necessary, by involving a third author to establish agreement (CF or PD). We assessed the following domains: sequence generation, allocation concealment, blinding of participants and personnel, blinding of outcome assessment, incomplete outcome data, and selective outcome reporting. We judged each domain in terms of there being a 'high', 'low', or 'unclear' risk of bias. We also assessed the influence of study sponsorship or funding sources as a potential source of bias. 


\section{Measures of treatment effect}

For dichotomous outcome data, we calculated risk ratios (RR) with 95\% confidence intervals (CI). For continuous outcome data, we calculated mean differences (MD) with $95 \%$ CIs. If we had pooled data for an outcome measured using different scales or scores, we would have used the standardized mean difference (SMD) with $95 \% \mathrm{CI}$. We reported the number needed to treat for an additional harmful outcome (NNTH) with $95 \%$ CI.

\section{Unit of analysis issues}

The unit of randomisation in the included studies was the individual participant'. However, one of the 29 participants in the microfracture group in Lim 2012 had bilateral surgery and the results for this group were presented by knees rather than participants. We judged that the disparity between the units of analysis and randomisation was likely to be small for this trial. As stated in our protocol we were alert to other unit of analysis issues, including those relating to trials with multiple treatment groups.

\section{Dealing with missing data}

We contacted authors to request any missing data, such as number of participants, age of participants, details of dropouts, means, measures of uncertainty (standard deviation or error), or number of events. When we failed to acquire missing data, we presented the available data and did not impute missing data.

\section{Assessment of heterogeneity}

The assessment of heterogeneity was done by visual inspection of forest plots. We used the $\mathrm{I}^{2}$ statistic to provide an objective measurement of statistical heterogeneity, as recommended by the Cochrane Handbook for Systematic Reviews of Interventions (Higgins 2011), with a rough guide for interpretation as follows: $0 \%$ to $40 \%$ indicates no significant heterogeneity; $30 \%$ to $60 \%$ may represent moderate heterogeneity; $50 \%$ to $90 \%$ may represent substantial heterogeneity; and $75 \%$ to $100 \%$ represents considerable heterogeneity (Deeks 2008).

\section{Assessment of reporting biases}

In a future update, if we include more than 10 studies, we plan to generate funnel plots to explore the possible existence of publication bias (Higgins 2011).

\section{Data synthesis}

When considered appropriate, the results of comparable groups of trials were pooled using either fixed-effect or random-effects models; both with $95 \%$ CIs. The choice of the model was guided by careful consideration of the extent of heterogeneity, and whether it could be explained, in addition to other factors such as the number and size of studies that are included. We considered not pooling data where there was considerable heterogeneity $\left(\mathrm{I}^{2}>75 \%\right)$ that could not be explained by the diversity of the clinical or methodological characteristics of the trials. Where it was not appropriate to pool data, we presented trial data in the analyses or tables for illustrative purposes and reported these results in the text.

\section{Subgroup analysis and investigation of heterogeneity}

No subgroup analyses were performed. In the future, with additional included trials and when sufficient data are available, we plan to perform subgroup analysis in order to explore different estimated effects across different population demographics and patient and injury parameter subgroups. Four subgroups were defined:

- Size of cartilage injury $\left(<2 \mathrm{~cm}^{2}\right.$ and $\left.>2 \mathrm{~cm}^{2}\right)$.

- Age of patients (under 45 years old and over 45 years old).

- Participant activity level (active and sedentary).

- Cartilage defects (chondral lesion) versus osteochondral defect (osteochondral lesion); subgroup analysis added after the protocol (seeDifferences between protocol and review).

Should we perform subgroup analysis in the future, we will investigate whether the results of subgroups are significantly different by inspecting the overlap of CIs and performing the test for subgroup differences that is available in RevMan.

\section{Sensitivity analysis}

When sufficient trials are available for future updates of the review, we will perform sensitivity analyses to examine various aspects of the trial and review methodology. This will include the effects of excluding trials at high or unclear risk of bias, such as selection bias arising from a lack of allocation concealment; trials including people with osteochondritis dissecans; trials reporting only shortterm outcomes (under one year); and trials only reported in conference abstracts. We will also investigate the effects of missing data and the statistical model selected for pooling (fixed-effect versus random-effects).

\section{'Summary of findings' tables}

We used the GRADE approach to assess the quality of evidence related to each of the key outcomes listed in Types of outcome measures (Schünemann 2011). We presented a 'Summary of findings' table for the only comparison tested in the review. We reported on all three primary outcomes in addition to the secondary outcomes of pain, and activity level assessed via the Tegner score. For both function and activity levels, we presented separate results for intermediate and long-term follow-up. 
RE S U L T S

\section{Description of studies}

\section{Results of the search}

We screened a total of 1372 records from the following databases: the Cochrane Bone, Joint and Muscle Trauma Group Specialised Register (17 records); CENTRAL (78 records); MEDLINE (280 records); EMBASE (506 records); SPORTDiscus (160 records);
LILACS (214 records); the WHO ICTRP (38 records); ClinicalTrials.gov (75 records); and the ISRCTN registry (4 records). We also identified one potentially eligible study from searching the ISAKOS congress meetings.

The search resulted in the identification of six reports of potentially eligible studies, for which full articles were obtained. After review, we included three studies (Gudas 2005 (published in three articles); Lim 2012; Ulstein 2014), and excluded one (Pearsall 2014). No ongoing studies were identified and no studies await classification.

Details of the search are illustrated in Figure 1.

Figure I. Study flow diagram

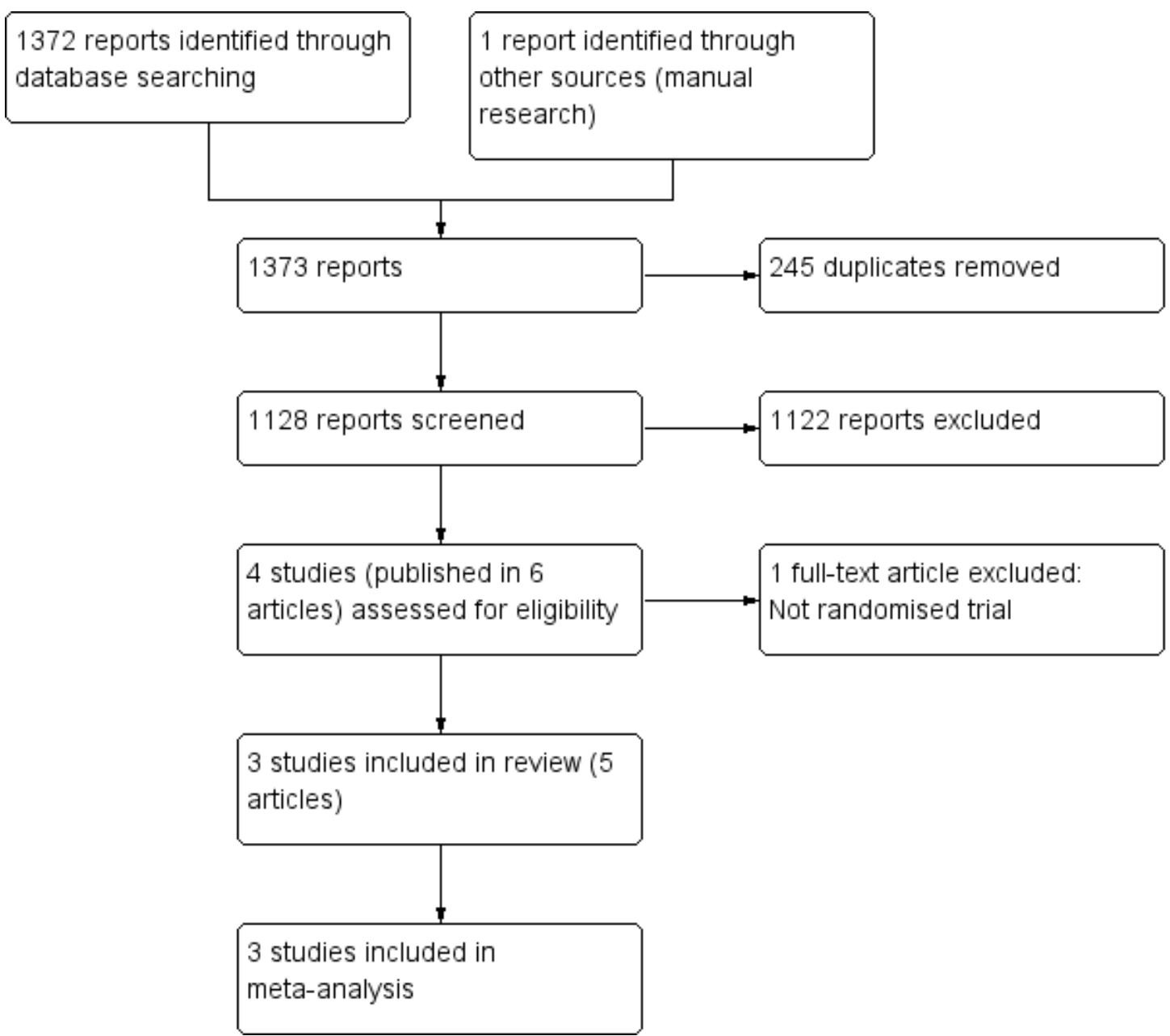




\section{Included studies}

Individual characteristics of the three included studies are presented in Characteristics of included studies.

One study was reported in three different reports (Gudas 2005); we extracted all data available from all reports. Additional study details and data were collected by communication with the contact authors of two studies (Lim 2012; Ulstein 2014). Details of the information obtained are given in the notes sections of Characteristics of included studies. All studies were published in English.

\section{Design}

The three included studies were randomised parallel-group controlled trials. Pre-published protocols or registration documents were not available for any trial.

\section{Setting}

Two studies were single-centre trials conducted in Lithuania and South Korea (Gudas 2005 and Lim 2012, respectively). Ulstein 2014 was a multi-centre trial conducted in three hospitals in Norway. All three trials recruited over several years: 1998 to 2002 (Gudas 2005); 2000 to 2008 (Lim 2012); and 2000 to 2006 (Ulstein 2014). Two trials had two treatment groups (Gudas 2005; Ulstein 2014). Lim 2012 had three treatment groups, but the participants in the third group, who were allocated to autologous chondrocyte implantation, were not eligible for inclusion in the review.

\section{Sample sizes}

The studies reported results for a total of 133 participants. Gudas 2005 randomised 60 people and reported results for 57 at followup. Lim 2012 randomised 109 people into three groups but did not report the numbers allocated into each group at randomisation; 40 participants (37\%) were excluded, leaving 51 participants (52 knees) followed up in the two treatment groups relevant to this review. Ulstein 2014 randomised and reported results for 25 participants.

\section{Participants}

Table 1 presents a summary of the key participant characteristics of each study. Gudas 2005 included young and highly competitive athletes (mean age 24.4 years), 63\% of whom were male. Lim 2012 included older participants (mean age 31.8 years), of whom 57\% were male. Ulstein 2014 included older participants (mean age 32.3 years), of whom $56 \%$ were male. Sport participation was not directly described in the latter two trials. Gudas 2005 included people with isolated cartilage lesions of ICRS grade 3 or 4 , symptomatic lesions due to osteochondral defect (osteo- chondritis dissecans), and localised defects on the medial and lateral femoral condyle $\left(1 \mathrm{~cm}^{2}\right.$ to $4 \mathrm{~cm}^{2}$ in area). Lim 2012 included people with symptomatic grade 3 and 4 lesions (Outerbridge grades; Outerbridge 1961), lesions of the medial or lateral femoral condyle, and defects of $1 \mathrm{~cm}^{2}$ to $4 \mathrm{~cm}^{2}$ in area. This study also included one participant with bilateral cartilage lesions. Ulstein 2014 included people with isolated cartilage lesions of ICRS grade 3 or 4, symptomatic lesions due to osteochondral defect (osteochondritis dissecans), or lesions located on the femoral condyle or trochlea with an area of $2 \mathrm{~cm}^{2}$ to $6 \mathrm{~cm}^{2}$ and depth $<10$ $\mathrm{mm}$. The mean duration of symptoms was 21.3 months in Gudas 2005 and 91.3 months in Ulstein 2014; no details on duration were provided in Lim 2012. Further details are presented in the 'Participants' section of Characteristics of included studies.

\section{Interventions}

All three included studies compared mosaicplasty with microfracture. Thus no study tested drilling or allograft transplantation. Gudas 2005 and Lim 2012 reported that both procedures were performed arthroscopically. Ulstein 2014 used minimally invasive arthrotomy. Rehabilitation, considered a co-intervention, was similar for both groups of participants in individual studies; however, each study adopted a different rehabilitation protocol (see Characteristics of included studies). Gudas 2005 did not use continuous passive motion, whereas Lim 2012 and Ulstein 2014 did.

\section{Outcomes}

All studies reported mostly the primary outcomes listed in our protocol (Gracitelli 2013). Knee function was assessed with at least two validated instruments (IKDC (within the ICRS evaluation package), HSS, Lysholm, KOOS) in all articles. Quality of life was assessed in Ulstein 2014 with the KOOS QOL. Failure of treatment and adverse effects were also assessed in all articles. Reported adverse effects were symptom recurrence and revision surgery. We also included superficial infection as a short-term adverse effect from Gudas 2005.

Secondary outcomes were reported in some studies. Ulstein 2014 reported on pain using the KOOS Pain subscale. Participant activity levels were assessed in all studies with the Tegner score; Gudas 2005 also used the categorisation of activity levels listed in the ICRS standard evaluation form, and Ulstein 2014 also used the KOOS Sport and Recreation subscale.

The quality of cartilage was assessed differently in the three trials. Gudas 2005 arthroscopically graded macroscopic appearance according to the ICRS in 34 participants at a mean of 12.4 months, performing biopsy in 25 cases; at 10 years follow-up, participants were submitted to magnetic resonance observation (MOCART) and radiographic examination, with evaluation based on the Kellgren and Lawrence criteria (Kellgren 1957; Kessler 1998). Lim 2012 performed 'second-look' arthroscopy on 52 knees (findings were assessed using the ICRS grading system) and MRI on 61 
knees (findings were assessed using the modified Outerbridge classification (Outerbridge 1961; Potter 1998). Ulstein 2014 reported radiographic evaluation based on the Kellgren and Lawrence criteria (Kellgren 1957). The Kellgren-Lawrence grading system is used to assess the severity of knee osteoarthritis and thus is used as a proxy for 'quality of cartilage' in our review.

Ulstein 2014 also reported isokinetic quadriceps and hamstring strength measurements; these outcomes were not listed in our protocol and thus not included in this review.

\section{Timing of outcome assessment}

The three reports of Gudas 2005 reported results at different follow-up times, ranging from short to long term. The first, published in 2005, reported results for three years follow-up (mean 37 months); the second, published in 2006, reported results at one, two, and three years follow-up; and the third, published in 2014, reported results at 10.4 years follow-up (range 9 to 11 years). Lim 2012 reported primary and secondary outcomes, mainly in the long term (mean 6.3 years, range 3.2 to 10.5 years) and Ulstein 2014 reported outcomes in the long-term (median 9.8 years, range 4.9 to 11.4 years).

\section{Excluded studies}

We excluded one study (Pearsall 2014) because of the lack of randomisation, as described in the Characteristics of excluded studies.

\section{Risk of bias in included studies}

The review authors' judgements of the risk of bias for each domain are detailed below and in the Characteristics of included studies, and summarised for each trial in Figure 2. Upon contact of trialists, information on random sequence generation was provided for two trials (Lim 2012; Ulstein 2014), and on the lack of blinding of functional outcomes but blinding of radiographic classification in Ulstein 2014. 
Figure 2. Risk of bias summary: review authors' judgements about each risk of bias item for each included study.

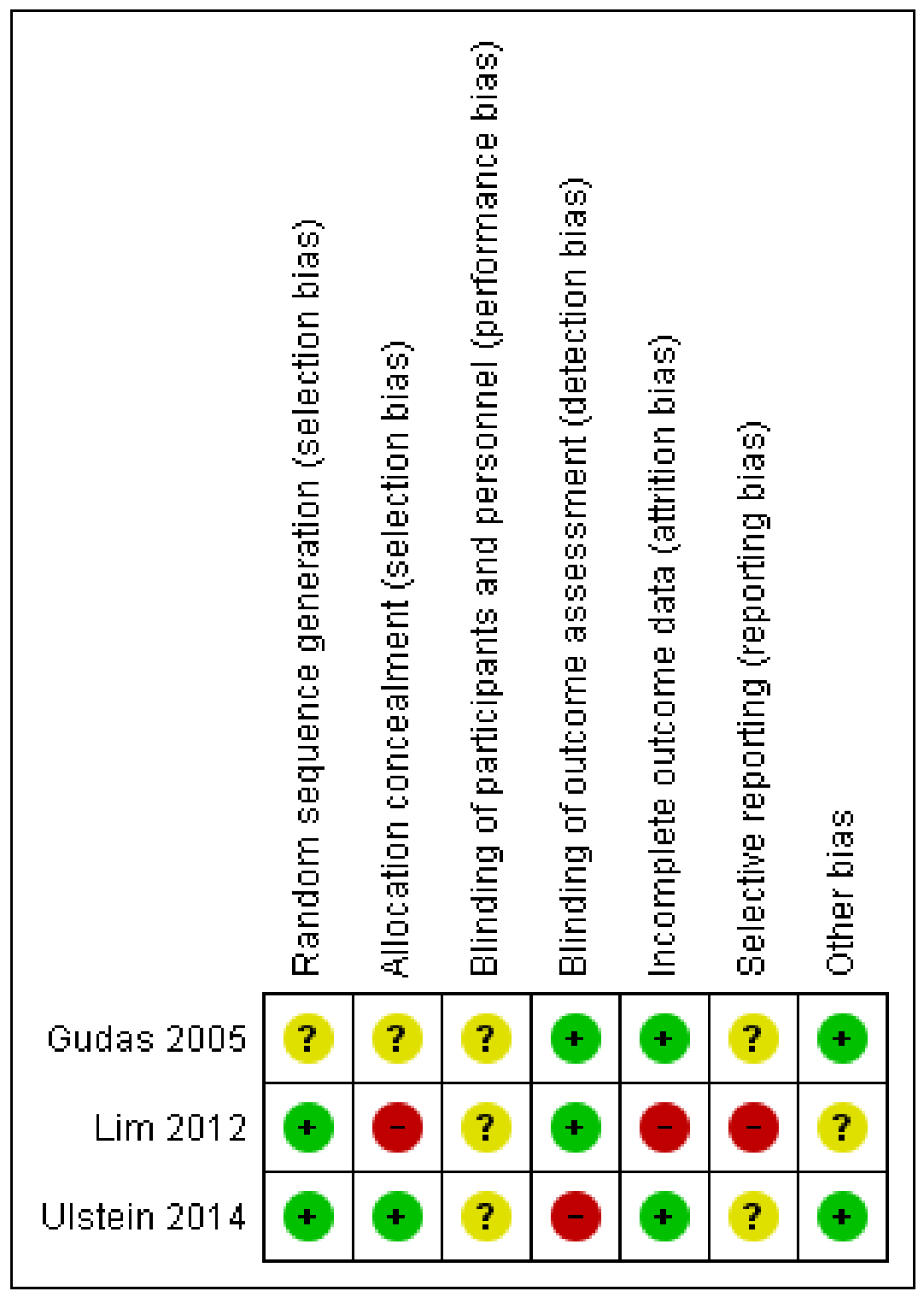

Surgical interventions (microfracture, drilling, mosaicplasty, and allograft transplantation) for treating isolated cartilage defects of the 


\section{Allocation}

Adequate methods of sequence generation were described in Lim 2012 and Ulstein 2014, which were both judged to be at low risk of bias for this domain. Gudas 2005 did not specify the method of sequence generation and was judged to be at unclear risk of bias. Sealed and opaque envelopes were used in two trials (Gudas 2005; Ulstein 2014), but only Ulstein 2014 provided sufficient assurance of concealment by their use of sequentially-numbered envelopes. Hence, Gudas 2005 was judged to be at unclear risk and Ulstein 2014 at low risk of selection bias relating to allocation concealment. Lim 2012 used sealed envelopes but provided no other mention of safeguards to ensure allocation concealment. Moreover, Lim 2012 reported that participants who disagreed with their allocated procedures were excluded; thus, the allocation process was also compromised, and the trial was judged to be at high risk.

\section{Blinding}

No blinding of surgeons was possible because of the inherent differences in the procedures. We judged there was an unclear risk of performance bias for all three trials.

Gudas 2005 reported completely blinding participants and the outcome assessment. The authors stated that only arthroscopic procedures were performed. Lim 2012 also performed all procedures arthroscopically, and had blinded assessors. Both trials were judged to be at low risk of detection bias. Since Ulstein 2014 performed a mini-arthrotomy in the mosaicplasty group, it was likely that participants and personnel might be aware of the type of surgery performed according to the scar on the knee. Ulstein 2014 confirmed by email that the assessment of functional outcomes was not blinded, and therefore this trial was judged to be at high risk of detection bias for the primary outcome. All studies reported blinded assessment of overall radiological (radiography and MRI) and histological evaluations.

\section{Incomplete outcome data}

Ulstein 2014 reported no follow-up loss, and Gudas 2005 reported small losses that were balanced between groups (two in the mosaicplasty group and one in the microfracture group). Lim 2012 excluded 40 participants (37\% of 109 included in the three group trial) after randomisation and did not state how many were randomised into each group. We judged Gudas 2005 and Ulstein 2014 to be at low risk of attrition bias, and Lim 2012 to be at high risk.

\section{Selective reporting}

None of the three studies provided a protocol or prospective trial registration. We judged Gudas 2005 and Ulstein 2014 as being at unclear risk of selective reporting but Lim 2012 at high risk because of the non-reporting of functional outcome data that appear to have been collected. Of note is that we do not have enough information to judge whether the two subgroups presented in Gudas 2005 were prespecified, which reinforces our judgement of unclear risk of bias.

\section{Other potential sources of bias}

No studies were sponsored by the industry of medical devices. Ulstein 2014 received a grant from a nonprofit foundation (Akershus University Hospital and the Foundation of Sophies Minde). No studies appeared to be influenced by any other study sponsorship or funding sources.

\section{Effects of interventions}

See: Summary of findings for the main comparison Mosaicplasty compared with microfracture for adults with isolated cartilage defects of the knee

All three trials compared mosaicplasty with microfracture. The results are presented as overall findings of the trials, including primary and secondary outcomes. Where available, separate data for function, activity, adverse effects, and return to normal daily activities are presented for three time periods: short-term (up to one year); intermediate-term (one up to five years); and long-term (five or more years). When trials included more than one measure of function, we chose the IKDC score (included in the ICRS cartilage injury evaluation package but referred to as ICRS scores in Gudas 2005) and Lysholm score rather than HSS score and KOOS score. Lysholm is the most commonly used in the literature and the combination of the five separate scores comprising the KOOS score is not recommended.

\section{Overall analysis of mosaicplasty versus microfracture}

\section{Function}

One trial reported intermediate term results (Gudas 2005) and all three presented long term results, although those reported for Lim 2012 ranged from 3 to 10.5 years.

Assessing function via the IKDC 2000 score (0 to 100, 100 being the best score), Gudas 2005 (57 participants) found a statistically significant and clinically important difference in favour of mosaicplasty at one year (MD 10.29, 95\% CI 7.87 to 12.71 ; very low quality evidence; see Analysis 1.1). This difference also continued at three years (mean 89 versus 75 ; reported $\mathrm{P}<0.001$ ). 
The other two trials assessed function via the Lysholm score $(0$ to 100,100 being the best score). Since the long term results for Gudas 2005 were markedly different and substantially heterogeneous from those of the other two trials, we did not pool the long term data from all three trials (see Analysis 1.2). Pooled Lysholm scores from Lim 2012 and Ulstein 2014 showed no clinically important difference between the two groups (MD -1.10, 95\% CI 4.54 to 2.33 ; 72 participants; very low quality evidence). Gudas 2005 presented function data subgrouped by whether the cartilage injury was caused by trauma (only chondral lesions) or by osteochondritis (osteochondral lesions); as the subgroup results were very similar, we combined these to produce a result for the overall group. As at intermediate follow-up, the findings of Gudas 2005 strongly favoured the mosaicplasty group (MD 13.97, 95\% CI 13.25 to $14.69 ; 57$ participants; very low quality evidence).

\section{Quality of life}

Ulstein 2014 found no significant between-group difference in long-term quality of life measured via the KOOS QOL score $(0$ to 100,100 being the best score; MD -7.00 favouring microfracture, $95 \%$ CI -25.23 to 11.23 ; 25 participants; very low quality evidence, see Analysis 1.3). The Minimal Detectable Change in patients with knee injury is 7 to 7.2 for KOOS QOL; KOOS.

\section{Failure of treatment and adverse effects}

All three trials reported on treatment failure. Only Gudas 2005 gave some details of the timing of 'failure', whereas Lim 2012 and Ulstein 2014 reported only on those requiring a re-operation during follow-up.

Gudas 2005 reported that two participants in the mosaicplasty group had superficial infections which resolved with antibiotics. They confirmed that there was no donor-site morbidity in this group.

There were some common characteristics in the reported failures and revision surgeries in the three trials. Gudas 2005 reported 10 failures (one mosaicplasty versus nine microfracture) occurring up to one year after surgery; revision surgery comprised mosaicplasty in eight of the nine microfracture participants. A further five patients experienced failure (two mosaicplasty versus three microfracture) at an average of 5.8 years in Gudas 2005, four of whom had revision surgery comprising mosaicplasty. A prominent osteochondral plug was reported as failed treatment prompting revision surgery in the mosaicplasty group of both Gudas 2005 and Lim 2012. Three microfracture participants also had re-operations in Lim 2012. Of the 11 re-operations or additional surgical procedures (five mosaicplasty versus six microfracture) in Ulstein 2014, all three participants having a second cartilage procedure belonged to the microfracture group; another participant in this group had a total joint replacement.

Pooled results for treatment failure reported at long-term followup in the three trials showed recurrence and re-operations were significantly fewer in the mosaicplasty group (10/64 versus 20/ 65; RR $0.47,95 \%$ CI 0.24 to 0.90 ; very low quality evidence; see Analysis 1.4). The majority of failures (10 of 15) in Gudas 2005 occurred by 12 month follow-up and were mainly for symptom recurrence; all had revision surgery. This result equates to an NNTH of 6 (95\% CI 4 to 34); hence, one additional person will have revision surgery for every six participants receiving microfracture rather than mosaicplasty over 10 years follow-up.

\section{Pain}

Measured using the pain component of the KOOS score (0 to 100, 100 being the best score), Ulstein 2014 found no significant between group difference in pain at 9.8 years follow-up (MD 7.50 favouring microfracture, $95 \%$ CI -26.06 to 11.06 ; 25 participants; very low quality evidence; see Analysis 1.5). The Minimal Detectable Change in patients with knee injury is 6 to 6.1 for KOOS Pain; KOOS.

\section{Activity}

All trials reported data regarding activity based on Tegner scores (1 to 10, 10 being the best score). The Tegner score results for Gudas 2005 are summed from separate subgroup data provided for chondral and osteochondral lesions; there was no evidence to support subgroup differences. The evidence for all activity results was rated very low quality.

Gudas 2005 reported higher Tegner scores in the mosaicplasty group at three-year (intermediate) follow-up (MD 0.48, 95\% CI 0.21 to 0.75 ; 57 participants; see Analysis 1.6), but the difference between the two groups may not be clinically important.

Because of clear statistical and clinical heterogeneity, we did not pool the long term Tegner score results (see Analysis 1.7). Gudas 2005 continued to report higher Tegner scores in the mosaicplasty group at 10 years follow-up (MD $0.72,95 \%$ CI 0.46 to $0.98 ; 57$ participants); but again the between group difference may not be clinically important. Lim 2012 found no difference between the two groups at an average of 6.3 years (MD 0.20, 95\% CI - 0.57 to 0.97; 47 participants). Ulstein 2014 found no significant between group difference in Tegner scores at 9.8 years follow-up: MD -1.04 favouring microfracture, $95 \%$ CI -2.56 to $0.48 ; 25$ participants. Only Gudas 2005 reported on the return to normal daily activities, which was expressed in terms of sports given that all participants in the trial had been athletes (see Analysis 1.8). Gudas 2005 found a greater return to a pre-injury level of sports activities in the mosaicplasty group (26/28 versus 15/29; RR $1.80,95 \%$ CI 1.24 to 2.59); return to sports activities occurred at a mean of 6.5 months. There was also greater sports continuation in the mosaicplasty group at three years (25/28 versus $8 / 29$; RR $3.24,95 \%$ CI 1.77 to 5.92$)$ and 10 years (10/28 versus 5/29; RR 2.07, $95 \%$ CI 0.81 to 5.30 ), although the $95 \%$ CI crossed the line of no effect for the latter. 


\section{Quality of cartilage}

Quality of cartilage was assessed with MRI (Outerbridge and MOCART scores), arthroscopic 'second-look' surgery, histological evaluation after cartilage biopsy and, as a proxy, radiographic imaging characteristics of arthritis.

Lim 2012 found little between-group difference in the numbers of participants with satisfactory cartilage characteristics (grades 1 and 2 of Outerbridge's modified classification system) on MRI assessment at one year follow-up (17/20 versus 20/25; RR 1.06, 95\% CI 0.81 to 1.39 ; 45 participants; very low quality evidence; see Analysis 1.9). The MRI results of all 57 participants followed up at 10 years in Gudas 2005 were assessed according to different items of the MOCART score. As shown in Analysis 1.9, there were more satisfactory results in the mosaicplasty group for most of the individual features (e.g. complete degree of defect repair and filling: $21 / 28$ versus $10 / 29$; RR $2.17,95 \%$ CI 1.26 to 3.75 ; intact subchondral bone: $26 / 28$ versus $12 / 29$; RR 2.24 , $95 \%$ CI 1.44 to 3.50$)$.

Pooled data for excellent or good results on arthroscopic 'secondlook' surgery conducted at around one year in a subgroup of participants from two trials did not show a difference between the two groups (25/31 versus 25/40; random-effects RR 1.28 , 95\% CI 0.74 to 2.21 ; $\mathrm{I}^{2}=67 \%$; 71 participants; very low quality evidence; see Analysis 1.10). Gudas 2005, reporting on a subgroup of 25 participants who were submitted to a "second look" surgery conducted on average at 12.4 months follow-up, found that all participants of the mosaicplasty group displayed hyaline cartilage of a normal appearance but none in the microfracture group (11/ 11 versus 0/14; RR 28.75, 95\% CI 1.88 to 439.84; very low quality evidence; see Analysis 1.11).

The radiographic characteristics of arthritis were based on the Kellgren and Lawrence classification system (Grade 1: doubtful narrowing of joint space and possible osteophytic lipping; Grade 2: definite osteophytes, definite narrowing of joint space; Grade 3: moderate multiple osteophytes, definite narrowing of joints space, some sclerosis and possible deformity of bone contour; Grade 4: large osteophytes, marked narrowing of joint space, severe sclerosis and definite deformity of bone contour; Kellgren 1957). Pooled data from two trials of participants with radiographically-defined osteoarthritis showed a significant difference in favour of mosaicplasty (9/40 versus $19 / 40$; RR $0.48,95 \%$ CI 0.25 to 0.92 ; $\mathrm{I}^{2}=$ $0 \%$; very low quality evidence; see Analysis 1.12 ).

\section{Sensitivity analyses}

Sensitivity analyses were not performed because of the small number of studies.

\section{DISCUSSION}

\section{Summary of main results}

Our systematic review included three randomised controlled trials, all of which compared mosaicplasty with microfracture for treating isolated cartilage defects of the knee in adults. These reported results for a total of 133 participants, of whom 79 (59\%) were male. Mean ages of trial participants in the three trials ranged between 24.4 and 32.3 years. No trials of allograft transplantation or drilling were identified. We presented data from three trials for several outcomes (function, quality of life, pain, activity, return to normal daily activities, quality of cartilage on MRI, quality of cartilage measured by the presence of hyaline cartilage). It is clear throughout that the results of one small trial involving athletes only strongly favoured mosaicplasty (Gudas 2005), while the findings of the other two small trials were more conservative (Lim 2012; Ulstein 2014). The main results of the mosaicplasty versus microfracture comparison are presented in Summary of findings for the main comparison and summarised below.

There is very low quality evidence from one single-centre trial (57 participants), recruiting athletes only, that mosaicplasty probably resulted in better patient-reported function at one, two, and three years follow-up compared with microfracture. Very low quality evidence from the same trial showed that this effect persisted in the long-term at 10 years follow-up. However, there is very low quality evidence from the two other trials (72 participants) of little difference in patient-reported function between the two groups at long-term follow-up. One trial (25 participants) provided very low quality evidence of no significant difference between the two groups in quality of life or pain at long-term follow-up. Pooled results for treatment failure, primarily symptom recurrence, reported at long-term follow-up in the three trials (129 participants) favoured mosaicplasty. Based on an illustrative risk of 379 treatment failures per 1000 patients treated with microfracture, there is very low quality evidence that 201 fewer patients (95\% CI 288 to 38 fewer) would have treatment failure after mosaicplasty. All three trials reported activity scores, but due to clear statistical and clinical heterogeneity, we did not pool the long term Tegner score results. There was very low quality evidence from one study (57 participants) of higher Tegner scores, indicating greater activity, in the intermediate-term and long-term in the mosaicplasty group; however, the between group difference may not be clinically important. The other two trials provided very low quality evidence of no difference between the two groups in activity scores.

\section{Overall completeness and applicability of evidence}

The limited evidence available is for the mosaicplasty versus microfracture comparison only. We found no trials of allograft transplantation or drilling. The three small heterogeneous trials included in this review provided data for a total of 133 participants undergoing treatment for isolated knee cartilage lesions. One trial 
recruited patients from three centres, whereas the other two were single-centre studies. Only a few participants were lost to followup in two trials (Gudas 2005; Ulstein 2014), but there was a large but not quantifiable loss to follow-up in Lim 2012. Where data for common outcomes were available (e.g. Tegner scores), we often did not pool these because of substantial statistical heterogeneity. Isolated cartilage lesions are relatively rare in clinical practice, which helps explain the few trials with long recruitment times noted in this review. Generally, meniscal and ligament injuries are concomitant lesions resulting from the same traumatic event. Hence, the majority of clinical trials available in the literature for cartilage lesion in the knee include meniscal and ligament injuries (Gudas 2013). Selecting patients with isolated lesions reduces confounding from other injuries; however, extrapolating the trial results to the more common presentations is not straightforward. Additionally, other patient characteristics may have influenced the results.

As illustrated in Table 1, the available baseline characteristics data show substantial differences in the trial populations. We suspect that heterogeneity in the trial results reflects in part the different populations in these trials. Although there is some overlap in terms of population selection for some characteristics, there is a notable contrast between Gudas 2005, which selected younger athletes with relatively small lesions presenting on average at 21.3 months, and Ulstein 2014, which featured a very substantial delay to treatment (mean 91.3 months) in a less active and older population. Mean lesion sizes were comparable in the three trials, but Ulstein 2014 included some participants with lesions greater 4.0 $\mathrm{cm}^{2}$. This is compatible with their decision to use mini-arthrotomy for mosaicplasty. To achieve a smooth cartilage surface after plug implantation, perpendicularity is considered crucial according to the originally described surgical technique (Hangody 1998). When more than one plug is required, it is more challenging to perform mosaicplasty arthroscopically, and hence the rationale for the adoption of mini-arthrotomy because of larger defects by Ulstein 2014. Gudas 2005 and Lim 2012 performed mosaicplasty arthroscopically in all cases independent of cartilage size. Previous case series studies that included microfracture have shown better results from microfracture with lesions less than $4 \mathrm{~cm}^{2}$ compared with larger lesions (Knutsen 2007; Steadman 2003). However, the consequences of including larger sized defects in Ulstein 2014 was not clear. Cartilage lesion location is controversial in terms of the extent to which it influences final microfracture and mosaicplasty outcomes (Kreuz 2006; Mithoefer 2006). Only Ulstein 2014 reported cartilage lesions in the trochlea (just two were included), whereas the other trials only included femoral condyle lesions. Notably, none of the studies included the more difficult-to-treat patella lesions. Concomitant pathologies such as patellofemoral instability, dysplasia and malalignment make patella lesions more challenging to treat as well as to study.

Higher preoperative activity rates (Tegner score $>4$ ) have been shown to influence the function and activity outcomes of mi- crofracture in other studies (Knutsen 2004; Mithoefer 2006). Moreover, younger patients have been shown to have higher function scores and greater cartilage filling on MRI (Knutsen 2007; Kreuz 2006; Mithoefer 2006). The lower duration of symptoms is also associated with higher function outcomes in some retrospective studies (Solheim 2016). Thus Gudas 2005 has a population that is likely to do better whatever the intervention used. Whether this partially explains the different results for this trial favouring mosaicplasty compared with the other two trials is not clear and there were no data for subgroup analyses, including our preplanned subgroup analyses, which included an age threshold of 45 years.

\section{Quality of the evidence}

The quality of evidence available was downgraded three levels for all outcomes for which data were presented. Thus, overall we judged the evidence to be of very low quality, which indicates that we are very uncertain about the estimates for all outcomes. The justification for downgrading for each outcome is summarised in the footnotes of Summary of findings for the main comparison. Where the evidence was available from Gudas 2005 alone, we downgraded it one level for serious limitations due to risk of bias (insufficient information about sequence generation and allocation concealment, lack of blinding of surgeons; possible selective reporting). Where evidence was available for either the other two trials or in combination with Gudas 2005, we downgraded it two levels for serious limitations in design and implementation that related to one or more domains at high risk of bias (e.g. lack of allocation concealment and lack of blinding of outcome assessment) as well as other domains at unclear risk of bias (see Figure 2).

Where evidence was available from a single-centre trial only (Gudas 2005; Lim 2012), we downgraded the evidence one level for indirectness. Single centre trials may include mainly experts and highly trained surgeons in cartilage treatments, specially in mosaicplasty treatment, which requires a longer time of training, especially when performed arthroscopically. This is because we are uncertain whether the results, which may reflect the special characteristics of the centre including the specific expertise of the operating surgeons, are applicable more generally.

We downgraded the evidence for intermediate- and long-term function one level for inconsistency, even though data pooling was not undertaken and evidenced of inconsistency was available only in the long term.

We downgraded the evidence for several outcomes (e.g. Lysholm scores, treatment failure) one level for serious imprecision reflecting wide confidence intervals, small sample size, or low numbers of events.

We did not downgrade for publication bias since we obtained no evidence of this. 


\section{Potential biases in the review process}

Our search was comprehensive with no language restrictions applied, but the availability of other trials, which are likely to have been small and unpublished, cannot be ruled out.

We followed our protocol where possible; the few differences between the review and the protocol methods are shown in the Differences between protocol and review. Two areas of difference lay in our post-protocol selection of functional scores for presentation and introduction of another subgroup analysis for future use. In our judgement, neither action would have introduced bias: there was consistency in the results of the different functional scores presented in the individual trial reports; and we did not perform the new subgroup analysis, which is set up should sufficient data be available in the future.

\section{Agreements and disagreements with other studies or reviews}

In the literature, there are many narrative and systematic reviews that address all of the different cartilage repair and reconstruction treatments, including some of the interventions included in this review. We found many narrative reviews (and discuss one of these; Gomoll 2010b), and three systematic reviews, that partially overlap with ours (Goyal 2013; Goyal 2014; Mithoefer 2009). The comprehensive instructional course lecture of Gomoll 2010b considers patient demand and lesion size as key determinant characteristics for treatment decisions. Based on the findings of Gudas 2005, Gomoll 2010b recommended mosaicplasty for patients with small lesions $\left(<4 \mathrm{~cm}^{2}\right)$ and high-demand athletes, and microfracture for patients with lower demands. Gomoll 2010b also points to surgeon preference and familiarity with the two techniques as having a role in decision making and concludes that the available surgical procedures should be seen as "complementary, rather than competitive, allowing treatment of the entire spectrum of lesions". Mithoefer 2009 included 28 studies, of which only six were randomised controlled trials; the others were prospective cohort, retrospective cohort and case series. Microfracture was the only intervention explored, and one of the reports, published in 2005 and included in our review, was also selected (Gudas 2005). The authors reported that microfracture improved knee function in all studies in the short term, but that these results showed no durability. MRI findings were variable and correlated with function outcomes, and they also suggested that the 'second-look' surgery with poor quality of tissue formed correlates with increased longterm failure rate. However, only three studies included 'secondlook' surgery as a primary outcome. Microfracture was not compared with any other techniques in this review. A key shortcoming of this review was the high heterogeneity, which we also found in our included participants, in lesion characteristics (acute, chronic, chondral, or osteochondral, location, number, and size), concomitant procedures (meniscal, high tibia osteotomy, and ligament re- construction), and participant age.

Both of the more recent systematic reviews also included randomised controlled trials or prospective cohorts (Goyal 2013; Goyal 2014). Goyal 2013 focused on microfracture and Goyal 2014 on mosaicplasty. Both included Gudas 2005 but presented the results from the three reports of this trial as if they were three separate studies; and both included Lim 2012. Goyal 2013 concluded that microfracture gave positive short-term results in younger patients and patients with only small lesions but that treatment failure occurred after five years regardless of cartilage lesion size. Goyal 2014 referred to the findings from Gudas 2005 in terms of positive results for mosaicplasty over microfracture for younger patients with small lesions, but concluded there was insufficient evidence in long-term follow-up to draw conclusions. Both reviews were biased because of the double counting of the short term results of Gudas 2005.

The findings of Gudas 2005 are influential in all four articles discussed above. We add a note of caution in that the results of one small single-centre trial may not be representative, even for the more specific population, and always require confirmation.

\section{AUTHORS, CONCLUSIONS}

\section{Implications for practice}

We found no evidence from RCTs on allograft transplantation or drilling. The very low quality evidence from RCTs comparing mosaicplasty with microfracture is insufficient to draw conclusions on the relative effects of these two interventions for treating isolated cartilage defects of the knee in adults. Of note is that treatment failure, with recurrence of symptoms, occurred with both procedures.

\section{Implications for research}

In recent years, the diagnosis of cartilage lesions has increased due to increased availability of non-invasive examination techniques (MRI) and incidental findings of cartilage lesions in commonly performed arthroscopic surgeries. Microfracture and mosaicplasty are internationally-available methods of treatment, whereas allograft transplantation remains limited predominantly because of supply issues. Drilling was believed to be associated with thermal necrosis of subchondral bone and was abandoned for many years. However, the development of small and arthroscopic drills with continuous irrigation and homogenous perforation of the subchondral bone has increased its use as a cartilage treatment option. These observations help explain the restriction in the current review to trials comparing microfracture and mosaicplasty.

Further RCTs, that conform to best methods and reporting standards, are needed to define the best surgical option for treating isolated cartilage defects. Ideally, such trials will be multi-centre in 
order to assure sufficient numbers of patients and increase external applicability. Well defined and described populations, broadly stratified by key characteristics relating to prognosis such as age and size of cartilage defect to facilitate subgroup analysis, are required. Validated patient-reported outcome scores of function with longterm follow-up (10 years) should be considered to assess the onset of adverse effects and the development of osteoarthritis. We propose that two key areas of research are trials including patients with large osteochondral lesions treated with reconstructive procedures (mosaicplasty versus allograft transplantation), with reparative procedures (microfracture versus drilling) reserved for solely chondral and smaller lesions.

\section{ACKNOWLEDGEMENTS}

We would like to thank Helen Handoll and Haris Vasiliadis for valuable feedback on drafts of the review; and Lindsey Elstub and Joanne Elliott for their support and advice. We are particularly grateful to Joanne Elliott for her help with the searches.

We are grateful to Paresh Jobanputra and Haris Vasiliadis for feedback and suggestions at editorial and external review of the protocol. We would also like to thank William D Bugbee for his support as a cartilage specialist.

This project was supported by the National Institute for Health Research via Cochrane Infrastructure funding to the Cochrane Bone, Joint and Muscle Trauma Group. The views and opinions expressed therein are those of the authors and do not necessarily reflect those of the Systematic Reviews Programme, NIHR, NHS or the Department of Health.

\section{REFER E NCES}

\section{References to studies included in this review}

\section{Gudas 2005 \{published data only\}}

* Gudas R, Gudaite A, Pocius A, Gudiene A, Cekanauskas

E, Monastyreckienè E, et al. Ten-year follow-up of

a prospective, randomised clinical study of mosaic osteochondral autologous transplantation versus microfracture for the treatment of osteochondral defects in the knee joint of athletes. American Journal of Sports Medicine 2012;40(11):2499-508. [DOI: 10.1177/ 0363546512458763]

Gudas R, Kalesinskas R, Kimtys V, Stankevicius E, Toliusis $\mathrm{V}$, Bernotavicius $\mathrm{G}$, et al. A prospective randomised clinical study of mosaic osteochondral autologous transplantation versus microfracture for the treatment of osteochondral defects in the knee joint in young athletes. Arthroscopy 2005;21(9):1066-75.

Gudas R, Stankevič ius E, Monastyreckienè E, Pranys D, Kalesinskas RJ. Osteochondral autologous transplantation versus microfracture for the treatment of articular cartilage defects in the knee joint in athletes. Knee Surgery, Sports Traumatology, Arthroscopy 2006;14(9):834-42.

Lim 2012 \{published data only\}

${ }^{*}$ Lim H-C, Bae J-H, Song S-H, Park Y-E, Kim S-J. Current treatments of isolated articular cartilage lesions of the knee achieve similar outcomes. Clinical Orthopaedics and Related Research 2012;470(8):2261-7. [DOI: 10.1007/ s11999-012-2304-9]

S-J Kim. Mosaicplasty was done arthroscopically [personal communication]. Email to: GC Gracitella 17 April 2014.

Ulstein 2014 \{published data only\}

Ulstein S. Final data for KOOS and Tegner scores, information on blinding [personal communication]. Email to: GC Gracitella 9 April 2015.

* Ulstein S, Årøen A, Røtterud JH, Løken S, Engebretsen
L, Heir S. Microfracture technique versus osteochondral autologous transplantation mosaicplasty in patients with articular chondral lesions of the knee: a prospective randomised trial with long-term follow-up. Knee Surgery, Sports Traumatology, Arthroscopy 2014;22(6):1207-15.

[DOI: $10.1007 / \mathrm{s} 00167-014-2843-6]$

\section{References to studies excluded from this review}

Pearsall 2014 \{published data only\} Pearsall TAW, Madanagopal SG, Hughey JT. Osteoarticular autograft and allograft transplantation of the knee: 3 year follow-up. Orthopedics 2014;8(31):1-16.

\section{Additional references}

\section{Bartlett 2005}

Bartlett W, Gooding CR, Carrington RWJ, Skinner JA, Briggs TWR, Bentley G. Autologous chondrocyte implantation at the knee using a bilayer collagen membrane with bone graft. A preliminary report. Journal of Bone and Joint Surgery - British Volume 2005;87(3):330-2.

\section{Bellamy 1988}

Bellamy N, Buchanan WW, Goldsmith CH, Campbell J, Stitt LW. Validation study of WOMAC: a health status instrument for measuring clinically important patient relevant outcomes to antirheumatic drug therapy in patients with osteoarthritis of the hip or knee. Journal of Rheumatology 1988;15(12):1833-40.

Bonzani 2006

Bonzani IC, George JH, Stevens MM. Novel materials for bone and cartilage regeneration. Current Opinion in Chemical Biology 2006;10(6):568-75.

\section{Brittberg 1994}

Brittberg M, Lindahl A, Nilsson A, Ohlsson C, Isaksson O, Peterson L. Treatment of deep cartilage defects in the knee 
with autologous chondrocyte transplantation. New England Journal of Medicine 1994;331(14):889-95.

\section{Brittberg 2003}

Brittberg M, Winalski CS. Evaluation of cartilage injuries and repair. Journal of Bone and Joint Surgery - American Volume 2003;85 Suppl 2:58-69.

\section{Buckwalter 1990}

Buckwalter JA, Rosenberg LC, Hunziker EB. Articular cartilage and knee joint function: basic science and arthroscopy. New York, Raven Press, 1990.

\section{Buckwalter 1992}

Buckwalter JA. Mechanical injuries of articular cartilage. The Iowa Orthopaedic Journal 1992;12:50.

\section{Bugbee 2002}

Bugbee WD. Fresh osteochondral allografts. Journal of Knee Surgery 2002;15(3):191-5.

\section{Bugbee 2012}

Bugbee W, Cavallo M, Giannini S. Osteochondral allograft transplantation in the knee. Journal of Knee Surgery 2012; 25(2):109-16.

\section{Davies-Tuck 2008}

Davies-Tuck ML, Wluka AE, Wang Y, Teichtahl AJ, Jones $\mathrm{G}$, Ding $\mathrm{C}$, et al. The natural history of cartilage defects in people with knee osteoarthritis. Osteoarthritis and Cartilage 2008;16(3):337-42.

\section{Deeks 2008}

Deeks JJ, Higgins JPT, Altman DG (editors). Chapter 9: Analysing data and undertaking meta-analyses. In: Higgins JPT, Green S (editors). Cochrane Handbook for Systematic Reviews of Interventions Version 5.1.0 [updated March 2011]. The Cochrane Collaboration, 2011. Available from www.cochrane-handbook.org.

\section{EuroQol Group 1990}

The EuroQol Group. EuroQol-a new facility for the measurement of health-related quality of life. Health Policy 1990;16:199-208.

\section{Flanigan 2010}

Flanigan DC, Harris JD, Trinh TQ, Siston RA, Brophy RH. Prevalence of chondral defects in athletes' knees: a systematic review. Medicine and Science in Sports and Exercise 2010;42(10):1795-801.

Ghazavi 2007

Ghazavi MT, Pritzker KP, Davis AM, Gross AE. Fresh osteochondral allografts for post-traumatic osteochondral defects of the knee. Journal of Bone and Joint Surgery British Volume 2007;79(6):1008-13.

\section{Gobbi 2005}

Gobbi A, Nunag P, Malinowski K. Treatment of full thickness chondral lesions of the knee with microfracture in a group of athletes. Knee Surgery, Sports Traumatology, Arthroscopy 2005;13(3):213-21.

\section{Gomoll 2010a}

Gomoll AH, Madry H, Knutsen G, Dijk N, Seil R, Brittberg $\mathrm{M}$, et al. The subchondral bone in articular cartilage repair: current problems in the surgical management. Knee Surgery, Sports Traumatology, Arthroscopy 2010;18(4):434-47.

\section{Gomoll 2010b}

Gomoll AH, Farr J, Gillogly SD, Kercher J, Minas T. Surgical management of articular cartilage defects of the knee. Journal of Bone and Joint Surgery - American Volume 2010;92(14):2469-90.

\section{Goyal 2013}

Goyal D, Keyhani S, Lee EH, Hui JH. Evidence-based status of microfracture technique: a systematic review of level I and II studies. Arthroscopy 2013;29(9):1579-88.

\section{Goyal 2014}

Goyal D, Keyhani S, Goyal A, Lee EH, Hui JH, Vaziri AS Evidence-based status of osteochondral cylinder transfer techniques: a systematic review of level I and II studies. Arthroscopy 2014;30(4):497-505.

Gracitelli 2015

Gracitelli GC, Meric G, Briggs DT, Pulido PA, McCauley JC, Belloti JC, et al. Fresh osteochondral allografts in the knee: comparison of primary transplantation versus transplantation after failure of previous subchondral marrow stimulation. American Journal of Sports Medicine 2015;43 (4):885-91.

\section{Gross 1975}

Gross AE, Silverstein EA, Falk J, Falk R, Langer F. The allotransplantation of partial joints in the treatment of osteoarthritis of the knee. Clinical Orthopedics and Related Research 1975;(108):7-14.

\section{Gudas 2013}

Gudas R, Gudaite A, Mickevicius T, Masiulis N, Simonaityte R, Cekanauskas E, et al. Comparison of osteochondral autologous transplantation, microfracture, or debridement techniques in articular cartilage lesions associated with anterior cruciate ligament injury: a prospective study with a 3-year follow-up. Arthroscopy 2013; 29(1):89-97.

\section{Hangody 1998}

Hangody L, Kish G, Karpati Z, Udvarhelyi I, Szigeti I, Bely $M$. Mosaicplasty for the treatment of articular cartilage defects: application in clinical practice. Orthopedics 1998; 21(7):751-6.

\section{Hangody 2008}

Hangody L, Vasarhelyi G, Hangody LR, Sukosd Z, Tibay G, Bartha L, et al. Autologous osteochondral grafting technique and long-term results. Injury 2008;39 Suppl 1: 32-9.

\section{Higgins 2011}

Higgins JPT, Altman DG, Gotzsche PC, Juni P, Moher D, Oxman AD, et al. The Cochrane Collaboration's tool for assessing risk of bias in randomised trials. BMJ 2011;343 (7829):5928.

\section{Irrgang 2001}

Irrgang JJ, Anderson AF, Boland AL, Harner CD, Kurosaka M, Neyret P, et al. Development and validation of the international Knee Documentation Committee subjective 
knee form. American Journal of Sports Medicine 2001;29(5): $600-13$.

\section{Johnson 2001}

Johnson LL. Arthroscopic abrasion arthroplasty: a review. Clinical Orthopaedics and Related Research 2001;(391 Suppl):306-17.

\section{Kaul 2012}

Kaul G, Cucchiarini M, Remberger K, Kohn D, Madry $H$. Failed cartilage repair for early osteoarthritis defects: a biochemical, histological and immunohistochemical analysis of the repair tissue after treatment with marrowstimulation techniques. Knee Surgery, Sports Traumatology, Arthroscopy 2012;20(11):2315-24.

Kellgren 1957

Kellgren JH, Lawrence JS. Radiological assessment of osteoarthrosis. Annals of the Rheumatic Diseases 1957;16(4):494502.

\section{Kessler 1998}

Kessler S, Guenther KP, Puhl W. Scoring prevalence and severity in gonarthritis: the suitability of the Kellgren \& Lawrence scale. Clinical Rheumatology 1998;17(3):205-9.

\section{Knutsen 2004}

Knutsen G, Engebretsen L, Ludvigsen TC, Drogset JO, Grøntvedt T, Solheim E, et al. Autologous chondrocyte implantation compared with microfracture in the knee. A randomized trial. Journal of Bone and Joint Surgery American Volume 2004;86(3):455-64.

\section{Knutsen 2007}

Knutsen G, Drogset JO, Engebretsen L, Grøntvedt T, Isaksen V, Ludvigsen TC, et al. A randomized trial comparing autologous chondrocyte implantation with microfracture: findings at five years. Journal of Bone and Joint Surgery - American Volume 2007;89(10):2105-12.

Kocher 2004

Kocher MS, Steadman JR, Briggs KK, Sterett WI, Hawkins RJ. Reliability, validity, and responsiveness of the Lysholm knee scale for various chondral disorders of the knee. Journal of Bone and Joint Surgery - American Volume 2004; 86(6):1139-45

\section{Kreuz 2006}

Kreuz PC, Steinwachs MR, Erggelet C, Krause SJ, Konrad $\mathrm{G}$, Uhl M, et al. Results after microfracture of full thickness chondral defects in different compartments in the knee. Osteoarthritis and Cartilage / OARS, Osteoarthritis Research Society 2006;14:1119-25.

\section{Krych 2012}

Krych AJ, Robertson CM, Williams RJ. Return to athletic activity after osteochondral allograft transplantation in the knee. American Journal of Sports Medicine 2012;40(5): 1053-9.

Lefebvre 2011

Lefebvre C, Manheimer E, Glanville J. Chapter 6: Searching for studies. In: Higgins JPT, Green S (editors). Cochrane Handbook for Systematic Reviews of Interventions Version
5.1.0 [updated March 2011]. The Cochrane Collaboration, 2011. Available from www.cochrane-handbook.org.

Lijoi 2001

Lijoi F, Lughi M, Baccarani G. Cartilaginous abrasion and debridement: correlation between type of cartilaginous injury and results in patients with a 4 to 9-year follow-up. La Chirurgia Degli Organi di Movimento 2001;86(3):231-7.

\section{Lukianov 1987}

Lukianov AV, Gillquist J, Grana WA, DeHaven KE. An anterior cruciate ligament evaluation format for assessment of artificial or autologous anterior cruciate results. Clinical Orthopaedic and Related Research 1987;(218):167-80.

Lysholm 1982

Lysholm J, Gillquist J. Evaluation of knee ligament surgery results with special emphasis on use of a scoring scale. American Journal of Sports Medicine 1982;10(3):150-4.

\section{Marcacci 2005}

Marcacci M, Berruto M, Brocchetta D, Delcogliano A Ghinelli D, Gobbi A, et al. Articular cartilage engineering with Hyalograft C: 3-year clinical results. Clinical Orthopaedic and Related Research 2005;(435):96-105.

\section{Masthoff 2005}

Masthoff E, Trompenaars F, Van Heck G, Hodiamont P, De Vries J. Validation of the WHO Quality of Life assessment instrument (WHOQOL-100) in a population of Dutch adult psychiatric outpatients. European Psychiatry 2005;20 (7):465-73

\section{Mithoefer 2006}

Mithoefer K, Williams RJ 3rd, Warren RF, Potter HG, Spock CR, Jones EC, et al. Chondral resurfacing of articular cartilage defects in the knee with the microfracture technique. Surgical technique. Journal of Bone and Joint Surgery - American Volume 2006;88(Suppl 1 Pt 2):294-304.

\section{Mithoefer 2009}

Mithoefer K, McAdams T, Williams RJ, Kreuz PC, Mandelbaum BR. Clinical efficacy of the microfracture technique for articular cartilage repair in the knee: An evidence-based systematic analysis. American Journal of Sports Medicine 2009;37(10):2053-63.

\section{Mithofer 2005}

Mithöfer K, Peterson L, Mandelbaum BR, Minas T. Articular cartilage repair in soccer players with autologous chondrocyte transplantation: functional outcome and return to competition. American Journal of Sports Medicine 2005;33(11):1639-46.

Nukavarapu 2013

Nukavarapu SP, Dorcemus DL. Osteochondral tissue engineering: Current strategies and challenges. Biotechnology Advances 2013;31(5):706-21.

\section{Outerbridge 1961}

Outerbridge RE. The etiology of chondromalacia patellae. Journal of Bone and Joint Surgery - British Volume 1961;43 (4):752-7. 


\section{Peterson 2010}

Peterson L, Vasiliadis HS, Brittberg M, Lindahl A. Autologous chondrocyte implantation: A long-term followup. American Journal of Sports Medicine 2010;38(6):111724.

\section{Potter 1998}

Potter HG, Linklater JM, Allen AA, Hannafin JA, Haas SB. Magnetic resonance imaging of articular cartilage in the knee: an evaluation with use of fast-spin-echo imaging. Journal of Bone and Joint Surgery - American Volume 1998; 80:1276-84

\section{Pridie 1959}

Pridie K. A method of resurfacing osteoarthritic knee joints. Journal of Bone and Joint Surgery - American Volume 1959; 41:618-9.

Revill 1976

Revill SI, Robinson JO, Rosen M, Hogg MI. The reliability of a linear analogue for evaluating pain. Anaesthesia 1976; 31(9):1191-8.

RevMan [Computer program]

The Nordic Cochrane Centre, The Cochrane Collaboration. Review Manager (RevMan). Version 5.3. Copenhagen: The Nordic Cochrane Centre, The Cochrane Collaboration, 2014 .

Roos 1998

Roos EM, Roos HP, Lohmander LS, Ekdahl C, Beynnon BD. Knee Injury and Osteoarthritis Outcome Score (KOOS) - development of a self-administered outcome measure. Journal of Orthopaedic and Sports Physical Therapy 1998;28(2):88-96.

Schünemann 2011

Schünemann HJ, Oxman AD, Higgins JPT, Vist GE, Glasziou P, Guyatt GH. Chapter 11: Presenting results and 'Summary of findings' tables. In: Higgins JPT, Green $S$ (editors), Cochrane Handbook for Systematic Reviews of Interventions Version 5.1.0 [updated March 2011]. The Cochrane Collaboration, 2011. Available from www.cochrane-handbook.org.

\section{Solheim 2010}

Solheim E, Hegna J, Oyen J, Austgulen OK, Harlem T, Strand T. Osteochondral autografting (mosaicplasty) in articular cartilage defects in the knee: results at 5 to 9 years. Knee 2010;17(1):84-7.

\section{Solheim 2016}

Solheim E, Hegna J, Inderhaug E, Øyen J, Harlem T, Strand T. Results at 10-14 years after microfracture treatment of articular cartilage defects in the knee. Knee Surgery, Sports Traumatology, Arthroscopy 2016;24(5):1587-93.

\section{Steadman 2003}

Steadman JR, Briggs KK, Rodrigo JJ, Kocher MS, Gill TJ, Rodkey WG. Outcomes of microfracture for traumatic chondral defects of the knee: average 11-year follow-up. Arthroscopy: The Journal of Arthroscopic and Related Surgery 2003;19(5):477-84.

Stoker 2012

Stoker A, Garrity JT, Hung CT, Stannard JP, Cook J. Improved preservation of fresh osteochondral allografts for clinical use. Journal of Knee Surgery 2012;25(2):117-25.

Strauss 2009

Strauss E, Schachter A, Frenkel S, Rosen J. The efficacy of intra-articular hyaluronan injection after the microfracture technique for the treatment of articular cartilage lesions. American Journal of Sports Medicine 2009;37(4):720-6.

Tegner 1985

Tegner Y, Lysholm J. Rating systems in the evaluation of knee ligament injuries. Clinical Orthopaedics and Related Research 1985;(198):43-9.

Vasiliadis 2010a

Vasiliadis HS, Wasiak J. Autologous chondrocyte implantation for full thickness articular cartilage defects of the knee. Cochrane Database of Systematic Reviews 2010, Issue 10. [DOI: 10.1002/14651858.CD003323.pub3]

\section{Vasiliadis 2010b}

Vasiliadis HS, Wasiak J, Salanti G. Autologous chondrocyte implantation for the treatment of cartilage lesions of the knee: a systematic review of randomized studies. Knee Surgery, Sports Traumatology, Arthroscopy 2010;18(12):164555.

Ware 1992

Ware JEJ, Sherbourne CD. The MOS 36-item short-form health survey (SF-36). I. Conceptual framework and item selection. Medical Care 1992 Jun;30(6):473-83.

Widuchowski 2007

Widuchowski W, Widuchowski J, Trzaska T. Articular cartilage defects: study of 25,124 knee arthroscopies. Knee 2007;14(3):177-82.

\section{References to other published versions of this review}

\section{Gracitelli 2013}

Gracitelli GC, Moraes VY, Franciozi CES, Luzo MV, Belloti JC. Surgical interventions (microfracture, drilling, mosaicplasty and allograft transplantation) for treating isolated cartilage defects of the knee in adults. Cochrane Database of Systematic Reviews 2013, Issue 7. [DOI: 10.1002/14651858.CD010675]

* Indicates the major publication for the study 


\section{CHARACTERISTICS OF STUDIES}

\section{Characteristics of included studies [ordered by study ID]}

\section{Gudas 2005}

Methods

Participants

Randomised controlled trial: use of sealed envelopes.

Participants were followed for three years (first and second reports) and for 10 years (third report). Follow-up assessors were blinded to outcomes

Trial location: Kaunas University Hospital, Kaunas, Lithuania; recruitment 1998 to 2002

Participants: 60 athletes with symptomatic isolated cartilage lesions in the knee were randomised to undergo either mosaicplasty (30 participants) or microfracture (30 participants). Mean age 24.3 years, range 15 to 40 . Three participants lost to follow-up: 57 were followed-up (28 versus 29)

Included participants: Adult athletes with isolated cartilage lesions of ICRS grade 3 or 4, symptomatic lesions due to osteochondral defect (osteochondritis dissecans), and localised defects on the medial and lateral femoral condyle $\left(1 \mathrm{~cm}^{2}\right.$ to $\left.4 \mathrm{~cm}^{2}\right)$

Excluded participants: Patients with generalised chondromalacia or osteoarthritis, lesions larger than $4 \mathrm{~cm}^{2}$ or smaller than $1 \mathrm{~cm}^{2}$, patients older than 41 years, and patients with any misalignment or instability of the knee

Age:

OAT group mean (SD): 24.6 years $(6.54)$

MF group mean (SD): 24.3 years $(6.80)$

Gender:

OAT group (number of men/women): 19/9

MF group (number of men/women): 17/12

Sports activity: All participants were athletes.

Duration of symptoms: 21.3 months (SD 5.6 months)

Interventions
This study included only all-arthroscopic mosaicplasty and microfracture procedures. No other incision was used

Mosaicplasty or osteochondral autograft transplantation:

Standard procedure described in literature with the arthroscopic osteochondral autograft transfer system (OATS; Arthrex®). An average of 4.3 osteochondral plugs (range 3 to 6 plugs) were used per surgery

\section{Microfracture:}

The standard MF procedure for cartilage defect lesions was performed. When treating OCD caused by osteochondritis dissecans, the OCD fragments were removed and debrided, and then the microfracture was performed

\section{Co-interventions:}

The same rehabilitation programme for both groups. In the first weeks, achieving full range of motion was emphasised. No continuous passive motion was used in either group. All participants were allowed to walk with crutches. Weight bearing was prohibited for 4 weeks. Partial weight bearing $(20 \mathrm{~kg})$ was permitted after 4 weeks. No postoperative brace was used. After 8 weeks, participants progressed to full weight bearing. Depending on the clinical status, participants were allowed to gradually return to sports at 4 to 6 months post-operation 
Gudas 2005 (Continued)

\begin{tabular}{|c|c|c|}
\hline Outcomes & \multicolumn{2}{|c|}{$\begin{array}{l}\text { Primary outcomes: } \\
\text { IKDC score (this is the } 2000 \text { version included in the ICRS cartilage injury evaluation } \\
\text { package but referred to as the ICRS score in this trial) } \\
\text { HSS Score } \\
\text { Failure: revision surgery } \\
\text { Complication: infection } \\
\text { Secondary outcomes: } \\
\text { Activity level: Tegner Activity Scale and ICRS (based on activity levels in the 'Standard } \\
\text { Evaluation Form') } \\
\text { Quality of cartilage: } \\
\text { "Second look arthroscopy": macroscopic ICRS grade and biopsy } \\
\text { Magnetic resonance observation of cartilage repair tissue score system (MOCART) }\end{array}$} \\
\hline Notes & \multicolumn{2}{|c|}{ No additional data retrieval was possible after multiple contact attempts } \\
\hline \multicolumn{3}{|l|}{ Risk of bias } \\
\hline Bias & Authors' judgement & Support for judgement \\
\hline $\begin{array}{l}\text { Random sequence generation (selection } \\
\text { bias) }\end{array}$ & Unclear risk & $\begin{array}{l}\text { Insufficient information about the se- } \\
\text { quence generation process to permit judge- } \\
\text { ment }\end{array}$ \\
\hline Allocation concealment (selection bias) & Unclear risk & $\begin{array}{l}\text { Used opaque and sealed envelopes; inade- } \\
\text { quate mention of safeguards }\end{array}$ \\
\hline $\begin{array}{l}\text { Blinding of participants and personnel } \\
\text { (performance bias) } \\
\text { All outcomes }\end{array}$ & Unclear risk & $\begin{array}{l}\text { Participants were blinded to the interven- } \\
\text { tion, but surgeons cannot be blinded for } \\
\text { different interventions }\end{array}$ \\
\hline $\begin{array}{l}\text { Blinding of outcome assessment (detection } \\
\text { bias) } \\
\text { All outcomes }\end{array}$ & Low risk & $\begin{array}{l}\text { A blinded observer performed preoperative } \\
\text { and follow-up outcome assessment }\end{array}$ \\
\hline $\begin{array}{l}\text { Incomplete outcome data (attrition bias) } \\
\text { All outcomes }\end{array}$ & Low risk & $\begin{array}{l}\text { Missing outcome data were balanced in } \\
\text { numbers across intervention groups. Only } \\
3 \text { participants ( } 2 \text { mosaicplasty, } 1 \text { microfrac- } \\
\text { ture) lost to follow-up }\end{array}$ \\
\hline Selective reporting (reporting bias) & Unclear risk & The study protocol is not available. \\
\hline Other bias & Low risk & $\begin{array}{l}\text { The study seems free of other sources of } \\
\text { bias. }\end{array}$ \\
\hline
\end{tabular}

Surgical interventions (microfracture, drilling, mosaicplasty, and allograft transplantation) for treating isolated cartilage defects of the 
Methods

Participants

Randomised controlled trial: use of sealed envelopes.

Participants were followed for a minimum of three years (mean 5.7 years; range 3 to 10 . 5 years for the whole trial; mean 6.3 years; range 3.2 to 10.5 years for the comparison included in review). Follow-up assessors were blinded to outcomes

Trial location: Korea University Medical Center, Guro Hospital; recruitment 2000 to 2008

Participants: follow-up results reported for 51 people with symptomatic isolated cartilage lesions in the knee randomised to undergo either mosaicplasty (22 participants) or microfracture (29 participants; 30 knees). Mean age: 31.8 years (range in whole trial: 18 to 42 years)

Included participants: Patients with symptomatic grades 3 and 4 lesions (Outerbridge grades), lesions of the medial or lateral femoral condyle and defects of $1 \mathrm{~cm}^{2}$ to $4 \mathrm{~cm}^{2}$ in area. One participant from the microfracture group had both knees included in the study

Excluded participants: Authors do not establish clear exclusion criteria, but of the 109 people in the trial ( 3 treatment groups), 29 participants were excluded because of incomplete follow-up ( 4 were lost to follow-up $\& 2$ died) and 11 participants were excluded because they had undergone a secondary arthroscopic procedure to treat ligament or meniscal injuries or intraarticular infections. The excluded participants were from all three groups of intervention (microfracture, mosaicplasty, and autologous chondrocyte implantation) but numbers of participants excluded from each group were not reported Demographic and outcome data are based on 51 participants ( 52 knees) after exclusion Age:

OAT group mean (range): 30.4 years (20 to 39 )

MF group mean (range): 32.9 years (22 to 42 )

Gender:

OAT group mean (number of men/women): 12/10

MF group (number of men/women): 17/12

Lesion size:

OAT group mean area (range): $2.75 \mathrm{~cm}^{2}\left(1.0 \mathrm{~cm}^{2}\right.$ to $\left.54.0 \mathrm{~cm}^{2}\right)$

MF group mean area (range): $2.77 \mathrm{~cm}^{2}\left(1.2 \mathrm{~cm}^{2}\right.$ to $\left.3.6 \mathrm{~cm}^{2}\right)$

Sports activity (Tegner activity level score pre-op):

OAT group mean (SD): 2.7 (1.5)

MF group mean (SD): 2.8 (1.4)

Duration of symptoms: not stated

Interventions

This study included only all-arthroscopic mosaicplasty and microfracture procedures Mosaicplasty or osteochondral autograft transplantation:

Standard procedure was performed and detailed. After debridement of the fibrillated cartilage, the size of the lesion was measured using a $5 \mathrm{~mm}$ graduated probe and size tamp. To prepare the recipient site, the recipient tube harvester was placed over the defect. The harvesting device was perpendicular to the articular surface at the time of graft harvest. The grafts were inserted congruently so that they were not proud or recessed and they were supported at the base of the bone tunnels. They used plugs of 4, 6 , and $8 \mathrm{~mm}$ in diameter. Each donor transplant was harvested with a larger $(0.1 \mathrm{~mm})$ cylinder, and the lesion was carved out with a smaller cylinder so that a press-fit transplantation of the osteochondral cylinder could be achieved. All plugs were placed at the same level with the healthy cartilage

\section{Microfracture:}

Surgical interventions (microfracture, drilling, mosaicplasty, and allograft transplantation) for treating isolated cartilage defects of the 
Lim 2012 (Continued)

Standard microfracture was performed and detailed. Cartilaginous remnants on the subchondral bone were debrided fully with an arthroscopic curette and shaver. Conical holes of $0.5 \mathrm{~mm}$ to $1 \mathrm{~mm}$ in diameter and $4 \mathrm{~mm}$ deep were punched throughout the defect at a distance of $3 \mathrm{~mm}$ to $4 \mathrm{~mm}$ apart with awls

Mosaicplasty:

Standard mosaicplasty performed arthroscopically.

Microfracture:

Standard microfracture performed arthroscopically.

Co-interventions:

The rehabilitation programme was the same for both groups and after all operative techniques. Participants were told to perform certain rehabilitative exercises using a continuous passive motion device 2 to 4 hours per day for 6 to 8 weeks. Participants were allowed to bear weight partially on their tiptoes for 6 to 8 weeks. After 8 weeks, full weight bearing was permitted, and the participants returned to work. Normal activities of daily living were resumed 4 to 6 months after treatment

$\begin{array}{ll}\text { Outcomes } & \text { Primary outcomes: } \\ & \text { Lysholm score } \\ & \text { HSS Score } \\ \text { Failure: revision surgery } \\ \text { Secondary outcomes: } \\ \text { Activity level: Tegner activity scale } \\ \text { Quality of cartilage: } \\ \text { "Second look arthroscopy": macroscopic ICRS grade } \\ \text { Magnetic resonance image (Outerbridge grade) }\end{array}$

Notes

The third treatment group of this study (autologous chondrocyte implantation) was not included in this review. This study also based its power analysis on a secondary outcome (arthroscopic evaluation) rather than the function outcomes

The contact author provided additional information by e-mail: mosaicplasty was done arthroscopically; use of a computer programme for sequence generation; and no protocol was ever registered

Risk of bias

\begin{tabular}{|c|c|c|}
\hline Bias & Authors' judgement & Support for judgement \\
\hline $\begin{array}{l}\text { Random sequence generation (selection } \\
\text { bias) }\end{array}$ & Low risk & $\begin{array}{l}\text { This was not stated in the paper, but it is } \\
\text { unclear due to lack of description. The au- } \\
\text { thor contacted said the randomisation was } \\
\text { done by a computer programme }\end{array}$ \\
\hline Allocation concealment (selection bias) & High risk & $\begin{array}{l}\text { Sealed envelopes were prepared, but there } \\
\text { was no mention if they were opaque. Four } \\
\text { patients were excluded because their choice } \\
\text { of surgical procedure influenced the surgi- } \\
\text { cal procedure chosen }\end{array}$ \\
\hline
\end{tabular}

Surgical interventions (microfracture, drilling, mosaicplasty, and allograft transplantation) for treating isolated cartilage defects of the 


\section{Lim 2012 (Continued)}

Blinding of participants and personnel Unclear risk (performance bias)

All outcomes

Blinding of outcome assessment (detection Low risk bias)

All outcomes

Incomplete outcome data (attrition bias) High risk All outcomes
Participants were blinded to the intervention, but surgeons cannot be blinded for different interventions

The outcome assessment was done by blinded persons.
109 participants (120 knees) were recruited into the 3 groups. Of these, the author excluded 29 participants (4 patients lost to follow-up, 23 did not have adequate serial functional scores at 1, 6, 12, 24 and 36 months postoperatively, and 2 participants died) and a further 11 participants who had undergone a secondary arthroscopic procedure unrelated to the cartilage procedure. The numbers randomised into the mosaicplasty and microfracture groups were not given

The study protocol was not registered. Outcomes were collected at regular intervals before 3 years and those without "adequate serial functional scores at $1,6,12$, 24 , and 36 months postoperatively" were excluded. Thus interim outcomes and outcome at 3 years were probably planned to be reported

Other bias

Unclear risk
One participant had both knees included in the study.

Ulstein 2014

Methods
Randomised controlled trial: participants were randomised utilising the block procedure, and allotments were kept in sealed, opaque envelopes. There were no blinded followup assessments of primary outcomes. Participants were followed for median 9.8 years (range 4.9 to 11.4 )

Trial location: 3 different hospitals in Norway: Martina Hansens Hospital, Bærum; Oslo University Hospital, Oslo; Akershus University Hospital, University of Oslo. Recruitment: November 2000 to June 2006

Participants: 25 adults with chondral lesion in the knee were randomised to undergo either mosaicplasty (14 participants) or microfracture (11 participants); all were followedup

Included participants: Adults with isolated cartilage lesions ICRS grade 3 or 4, adults with symptomatic lesions due to osteochondral defect (osteochondritis dissecans), or 
lesions located on the femoral condyle or trochlea, with an area between $2 \mathrm{~cm}^{2}$ and 6 $\mathrm{cm}^{2}$ and depth $<10 \mathrm{~mm}$. Participants had to be 18 to 50 years of age with Lysholm score $<80$ and Tegner score $<6$

Excluded participants: Patients with radiographic osteoarthritis, major misalignment, major ligament injury or instability, extension deficit $>3$ degrees, flexion deficit $>5$ degrees and chondral lesions of ICRS grade 3 or 4 on the tibial plateau or patella. Patients had contralateral impaired knee function that could have influenced their ability to follow the rehabilitation protocol

Age:

OAT group mean (SD): 32.7 years (7.8)

MF group mean (SD): 31.7 years (8.0)

Gender:

OAT group (number of men/women): $8 / 6$

MF group (number of men/women): $6 / 5$

Lesion size:

OAT group median area (range): $3.0 \mathrm{~cm}^{2}\left(2.0 \mathrm{~cm}^{2}\right.$ to $\left.6.0 \mathrm{~cm}^{2}\right)$

MF group median area (range): $2.6 \mathrm{~cm}^{2}\left(2.0 \mathrm{~cm}^{2}\right.$ to $\left.5.2 \mathrm{~cm}^{2}\right)$

Sports activity (Tegner activity level score pre-op):

OAT group median (range): 2.5 (0 to 4 )

MF group median (range): 3 (0 to 4 )

Duration of symptoms:

OAT group mean (SD): 75.8 (73.5) months

MF group mean (SD): 111.0 (75.8) months

Interventions

This study included OAT/mosaicplasty performed through a medial parapatellar arthrotomy or a mini-invasive arthrotomy. Microfracture was performed all-arthroscopically Mosaicplasty or osteochondral autograft transplantation:

Standard procedure described in the literature with press-fit fixation (Acufex: Smith\& Nephew)

Mosaicplasty was performed through a medial parapatellar arthrotomy or a mini-invasive arthrotomy, depending on the lesion size and localization. Debridement was done similar to that described for MF. The OAT mosaicplasty procedure was performed by obtaining small cylindrical osteochondral grafts $(3.5 \mathrm{~mm}, 4.5 \mathrm{~mm}$, or $6.6 \mathrm{~mm}$ in diameter) from the minimal weight-bearing periphery of the femoral condyles and transplanting them "press-fit" to recipient tunnels in the prepared lesion site. At the end of the procedure, the knee was moved through a full range of motion to check the stability of the osteochondral plugs

\section{Microfracture:}

The procedure was arthroscopic and followed the standard procedures. Debridement of all damaged and unstable cartilage was performed, so as to obtain stable and healthy cartilage edges. An arthroscopic awl (Linvatec) was then used to perform multiple holes ("microfractures") about $3 \mathrm{~mm}$ to $4 \mathrm{~mm}$ apart. The depth of the holes was considered appropriate when "fat-pearls" emerged from the subchondral bone

\section{Co-interventions:}

The same rehabilitation program for both groups. All participants were hospitalised for a minimum of 5 days. Continuous passive motion (Kinetec ${ }^{\circledR}$ ) 3-4 H 2x/day began on the first post-operative day and continued for four days. Cold therapy and compression (Aircast Knee Cryo/Cuff $®$ ) were applied the two first days post-operation A maximum load of $15 \mathrm{~kg}$ to $20 \mathrm{~kg}$ weight bearing was allowed the initial 6 weeks post- 
Ulstein 2014 (Continued)

operation, gradually discontinuing the use of crutches up to 8 weeks. From 8 weeks, progression to full weight bearing was encouraged. Physiotherapist-guided rehabilitation was initiated immediately post-operation and was continued for a minimum of 6 months. Participants were generally allowed return to full activity after 6 months. However, participation in competitive contact sports or other activities that could expose the knee to pivoting forces was discouraged until 12 months post-operation

$\begin{array}{ll}\text { Outcomes } & \text { Primary outcomes: } \\ \text { Lysholm Score } \\ \text { KOOS } \\ \text { Failure: revision surgery (reoperation: ACI, OAT, proximal tibia osteotomy, loose body, } \\ \text { debridement, and knee replacement) } \\ \text { Complication: No complication mentioned } \\ \text { Secondary outcomes: } \\ \text { Activity level: Tegner activity scale } \\ \text { Quality of cartilage: } \\ \text { Radiographic arthrosis evaluation with Kellgreen and Lawrence criteria }\end{array}$

Risk of bias

\begin{tabular}{l|l|l}
\hline Bias & Authors' judgement & Support for judgement \\
\hline $\begin{array}{l}\text { Random sequence generation (selection } \\
\text { bias) }\end{array}$ & Low risk & $\begin{array}{l}\text { A block randomisation was performed with } \\
\text { a block size of } 10 \text { participants }\end{array}$ \\
\hline Allocation concealment (selection bias) & Low risk & $\begin{array}{l}\text { Used sequentially-numbered, opaque, and } \\
\text { sealed envelopes. }\end{array}$ \\
\hline
\end{tabular}

Blinding of participants and personnel Unclear risk (performance bias)

There was no blinding of participant and

All outcomes personnel.

Blinding of outcome assessment (detection High risk bias)

There was no blinding of primary outcomes.

All outcomes 
Ulstein 2014 (Continued)

\begin{tabular}{l|l|l}
\hline $\begin{array}{l}\text { Incomplete outcome data (attrition bias) } \\
\text { All outcomes }\end{array}$ & Low risk & No participants were lost to follow-up. \\
\hline Selective reporting (reporting bias) & Unclear risk & No protocol was available for comparison. \\
\hline Other bias & Low risk & $\begin{array}{l}\text { The study received grant support from Ak- } \\
\text { ershus University Hospital and the Foun- } \\
\text { dation of Sophies Minde. This foundation } \\
\text { is a non-profit institution and the study is } \\
\text { not biased by this grant }\end{array}$ \\
\hline
\end{tabular}

ACI: autologous chondrocyte implantation

HSS: Hospital for Special Surgery

ICRS: International Cartilage Repair Society

IKDC: International Knee Documentation Committee

KOOS: Knee Injury and Osteoarthritis Outcome Score

OAT: osteochondral autograft transfer, i.e. mosaicplasty

OCD: osteochondral defect

MF: microfracture

SD: standard deviation

Characteristics of excluded studies [ordered by study ID]

\begin{tabular}{ll}
\hline Study & Reason for exclusion \\
\hline Pearsall 2014 & Not a randomised clinical trial. Patient allocation was based on health insurance conditions \\
\hline
\end{tabular}


DATA AND ANALYSES

Comparison 1. Mosaicplasty versus microfracture

\begin{tabular}{|c|c|c|c|c|}
\hline Outcome or subgroup title & $\begin{array}{l}\text { No. of } \\
\text { studies }\end{array}$ & $\begin{array}{c}\text { No. of } \\
\text { participants }\end{array}$ & Statistical method & Effect size \\
\hline $\begin{array}{l}1 \text { Function (all } \\
\text { scores/instruments): } \\
\text { intermediate term (1 to } 5 \text { years } \\
\text { of follow-up) }\end{array}$ & 1 & & Mean Difference (IV, Fixed, 95\% CI) & Totals not selected \\
\hline 1.1 IKDC 2000 score & 1 & & Mean Difference (IV, Fixed, 95\% CI) & $0.0[0.0,0.0]$ \\
\hline $\begin{array}{l}2 \text { Function (all } \\
\text { scores/instruments): long term } \\
\text { ( } 5 \text { or more years of follow-up) }\end{array}$ & 3 & & Mean Difference (IV, Fixed, 95\% CI) & Subtotals only \\
\hline 2.1 Lysholm score & 2 & 72 & Mean Difference (IV, Fixed, 95\% CI) & $-1.10[-4.54,2.33]$ \\
\hline 2.2 IKDC 2000 score & 1 & 57 & Mean Difference (IV, Fixed, 95\% CI) & $13.97[13.25,14.69]$ \\
\hline $\begin{array}{l}3 \text { Quality of life: long-term (5 or } \\
\text { more years of follow-up) }\end{array}$ & 1 & & Mean Difference (IV, Fixed, 95\% CI) & Totals not selected \\
\hline $\begin{array}{l}4 \text { Failure of treatment and adverse } \\
\text { effects: long-term ( } 5 \text { or more } \\
\text { years of follow-up) }\end{array}$ & 3 & 129 & Risk Ratio (M-H, Fixed, 95\% CI) & $0.47[0.24,0.90]$ \\
\hline $\begin{array}{l}5 \text { Pain: long-term ( } 5 \text { or more years } \\
\text { of follow-up) }\end{array}$ & 1 & & Mean Difference (IV, Fixed, 95\% CI) & Totals not selected \\
\hline $\begin{array}{l}6 \text { Activity (Tegner score; } 1 \text { to } 10 \text { : } \\
\text { best score): intermediate term } \\
\text { (1 to } 5 \text { years follow-up) }\end{array}$ & 1 & & Mean Difference (IV, Fixed, 95\% CI) & Totals not selected \\
\hline 6.13 years follow-up & 1 & & Mean Difference (IV, Fixed, 95\% CI) & $0.0[0.0,0.0]$ \\
\hline $\begin{array}{l}7 \text { Activity (Tegner score; } 1 \text { to } 10 \text { : } \\
\text { best score): long term ( } 5 \text { or } \\
\text { more years follow-up) }\end{array}$ & 3 & & Mean Difference (IV, Fixed, 95\% CI) & Totals not selected \\
\hline 7.1 Mean 10.4 years follow-up & 1 & & Mean Difference (IV, Fixed, 95\% CI) & $0.0[0.0,0.0]$ \\
\hline 7.2 Mean 6.3 years follow-up & 1 & & Mean Difference (IV, Fixed, 95\% CI) & $0.0[0.0,0.0]$ \\
\hline $\begin{array}{l}\text { 7.3 Median } 9.8 \text { years } \\
\text { follow-up }\end{array}$ & 1 & & Mean Difference (IV, Fixed, 95\% CI) & $0.0[0.0,0.0]$ \\
\hline 8 Sports activity & 1 & & Risk Ratio (M-H, Fixed, 95\% CI) & Totals not selected \\
\hline $\begin{array}{l}8.1 \text { Return to same level of } \\
\text { pre-injury sport activities }\end{array}$ & 1 & & Risk Ratio (M-H, Fixed, 95\% CI) & $0.0[0.0,0.0]$ \\
\hline $\begin{array}{l}8.2 \text { Continuation of sports at } \\
3 \text { years }\end{array}$ & 1 & & Risk Ratio (M-H, Fixed, 95\% CI) & $0.0[0.0,0.0]$ \\
\hline $\begin{array}{l}8.3 \text { Continuation of sports at } \\
10 \text { years }\end{array}$ & 1 & & Risk Ratio (M-H, Fixed, 95\% CI) & $0.0[0.0,0.0]$ \\
\hline $\begin{array}{l}9 \text { Quality of cartilage at long-term } \\
\text { follow-up: magnetic resonance } \\
\text { image (satisfactory cartilage } \\
\text { characteristics) }\end{array}$ & 2 & & Risk Ratio (M-H, Fixed, 95\% CI) & Totals not selected \\
\hline 9.1 Outerbridge & 1 & & Risk Ratio (M-H, Fixed, 95\% CI) & $0.0[0.0,0.0]$ \\
\hline $\begin{array}{l}\text { 9.2 Mocart Score } \text { Degree of } \\
\text { defect repair and filling }\end{array}$ & 1 & & Risk Ratio (M-H, Fixed, 95\% CI) & $0.0[0.0,0.0]$ \\
\hline
\end{tabular}

Surgical interventions (microfracture, drilling, mosaicplasty, and allograft transplantation) for treating isolated cartilage defects of the 33 knee in adults (Review)

Copyright $\odot 2016$ The Cochrane Collaboration. Published by John Wiley \& Sons, Ltd. 
9.3 Mocart Score Integration to border zone

9.4 Mocart Score Surface of the repair tissue

9.5 Mocart Score 'Structure of the repair tissue

9.6 Mocart Score Subchondral lamina

9.7 Mocart Score 'Subchondral bone

9.8 Mocart Score Adhesion

9.9 Mocart Score Effusion

10 Quality of cartilage:

"Second-look" arthroscopy at around 1 year. Excellent and good

11 Quality of cartilage: presence of hyaline cartilage in biopsy

12 Quality of cartilage at long term follow-up: signs of radiographic osteoarthritis
Risk Ratio (M-H, Fixed, 95\% CI)

Risk Ratio (M-H, Fixed, 95\% CI)

Risk Ratio (M-H, Fixed, 95\% CI)

Risk Ratio (M-H, Fixed, 95\% CI)

Risk Ratio (M-H, Fixed, 95\% CI)

Risk Ratio (M-H, Fixed, 95\% CI)

Risk Ratio (M-H, Fixed, 95\% CI)

71

Risk Ratio (M-H, Random, 95\% CI)

Risk Ratio (M-H, Fixed, 95\% CI)

80
$0.0[0.0,0.0]$

$0.0[0.0,0.0]$

$0.0[0.0,0.0]$

$0.0[0.0,0.0]$

$0.0[0.0,0.0]$

$0.0[0.0,0.0]$

$0.0[0.0,0.0]$

$1.28[0.74,2.21]$

Totals not selected

$0.48[0.25,0.92]$

\section{Analysis I.I. Comparison I Mosaicplasty versus microfracture, Outcome I Function (all scores/instruments): intermediate term ( 1 to 5 years of follow-up).}

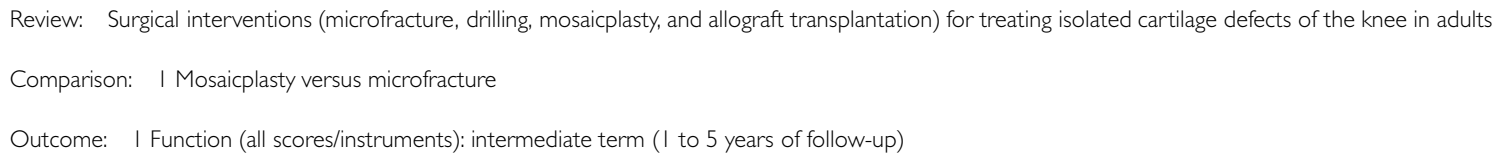

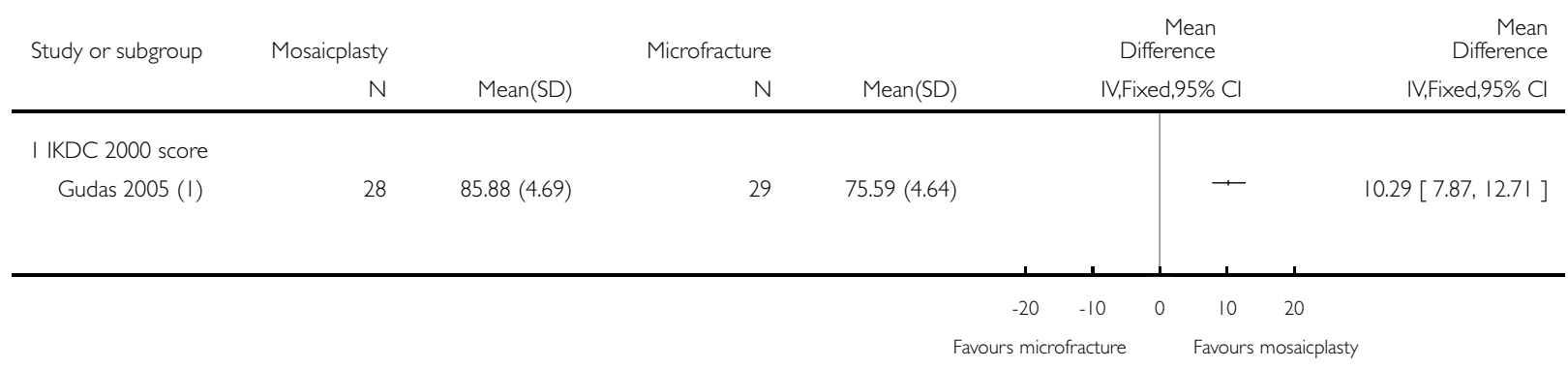

( I) 3 years follow-up: overall lesion (IKDC score 0-100: best score) 


\section{Analysis I.2. Comparison I Mosaicplasty versus microfracture, Outcome 2 Function (all scores/instruments): long term (5 or more years of follow-up).}

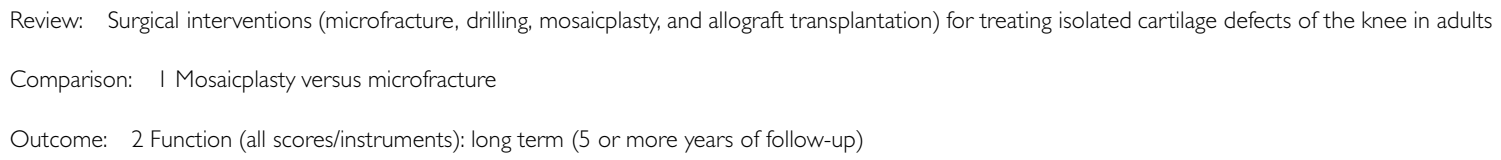

Subtotal $(\mathbf{9 5 \%} \mathrm{CI})$

Heterogeneity: not applicable

Test for overall effect: $Z=37.80(P<0.00001)$

(I) mean 6.3 years follow-up (Lysholm 0 to 100: best score)

(2) Median 9.8 years follow-up (Lysholm score 0 to 100: best score)

(3) Mean 10.4 years follow-up (IKDC score 0 to 100: best score) 
Analysis I.3. Comparison I Mosaicplasty versus microfracture, Outcome 3 Quality of life: long-term (5 or more years of follow-up).

Review: Surgical interventions (microfracture, drilling, mosaicplasty, and allograft transplantation) for treating isolated cartilage defects of the knee in adults

Comparison: I Mosaicplasty versus microfracture

Outcome: 3 Quality of life: long-term (5 or more years of follow-up)

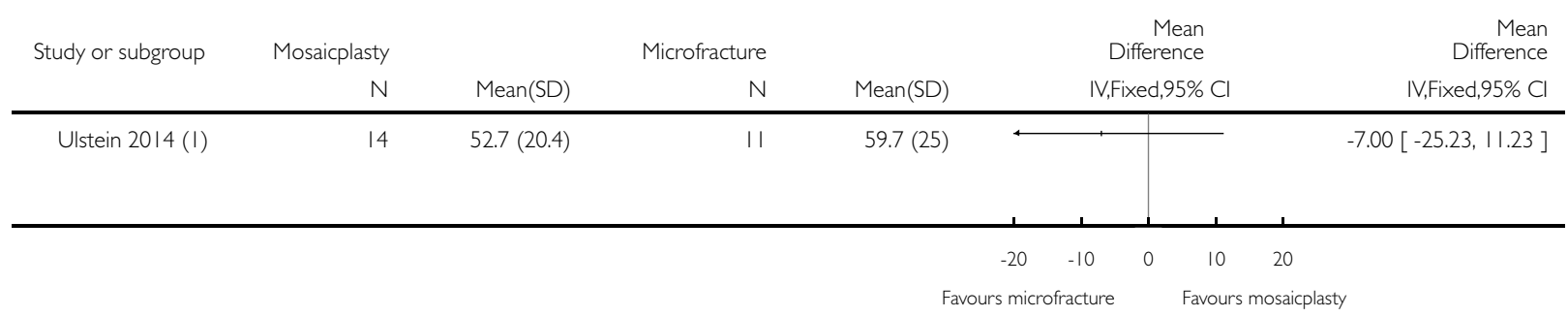

(I) median 9.8 years follow-up (KOOS QoL: 0 to 100=best score)

Analysis I.4. Comparison I Mosaicplasty versus microfracture, Outcome 4 Failure of treatment and adverse effects: long-term (5 or more years of follow-up).

Review: Surgical interventions (microfracture, drilling, mosaicplasty, and allograft transplantation) for treating isolated cartilage defects of the knee in adults

Comparison: I Mosaicplasty versus microfracture

Outcome: 4 Failure of treatment and adverse effects: long-term ( 5 or more years of follow-up)

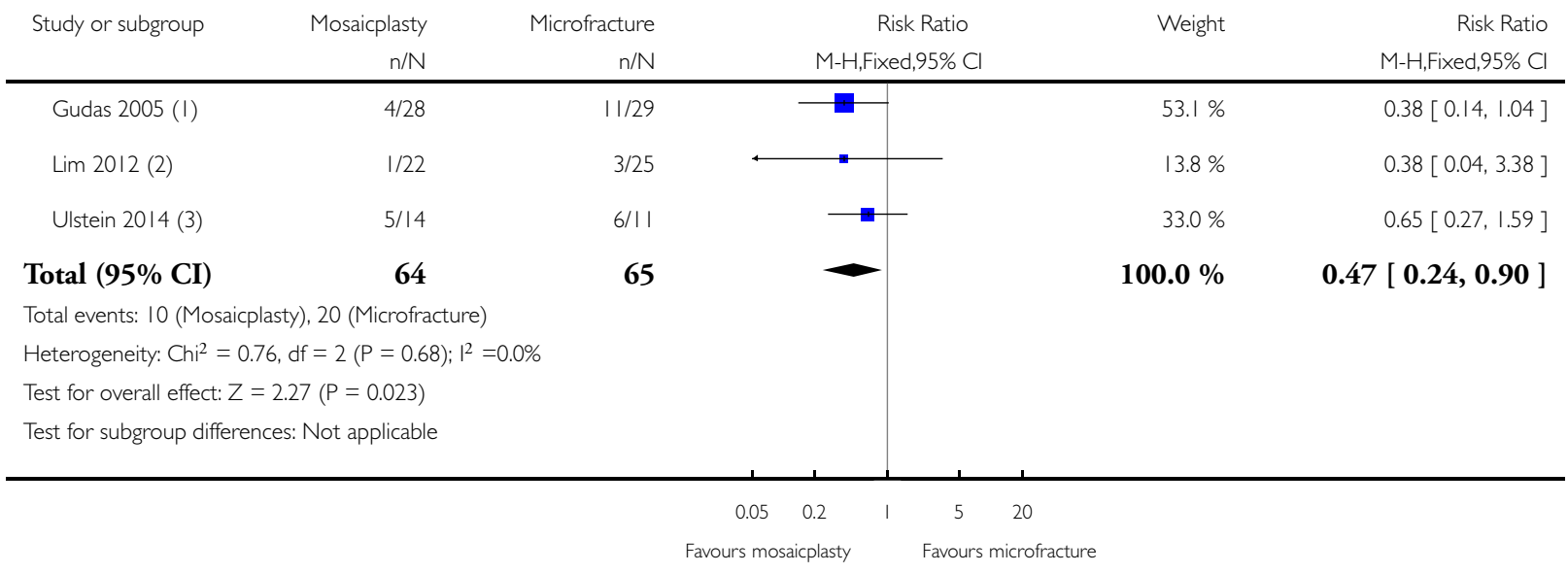

Surgical interventions (microfracture, drilling, mosaicplasty, and allograft transplantation) for treating isolated cartilage defects of the knee in adults (Review)

Copyright $\odot 2016$ The Cochrane Collaboration. Published by John Wiley \& Sons, Ltd. 

( I) Revision surgery and symptom recurrence
(2) Revision surgery
(3) Revision surgery

\section{Analysis I.5. Comparison I Mosaicplasty versus microfracture, Outcome 5 Pain: long-term (5 or more} years of follow-up).

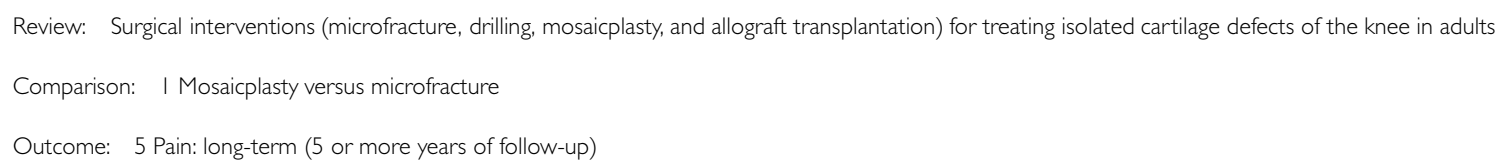

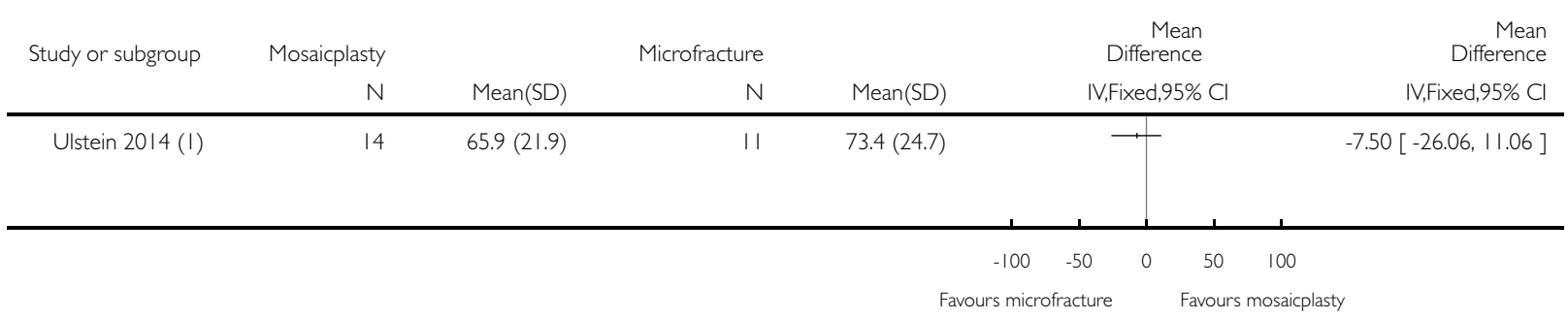

(1) median 9.8 years follow-up (KOOS pain: 0 - $100=$ best score) 
Analysis I.6. Comparison I Mosaicplasty versus microfracture, Outcome 6 Activity (Tegner score; I to I0: best score): intermediate term ( $I$ to 5 years follow-up).

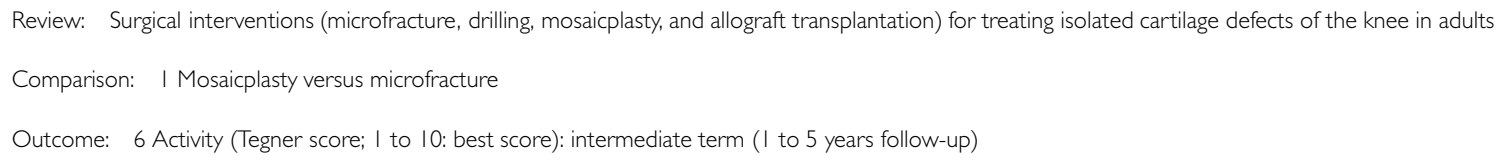

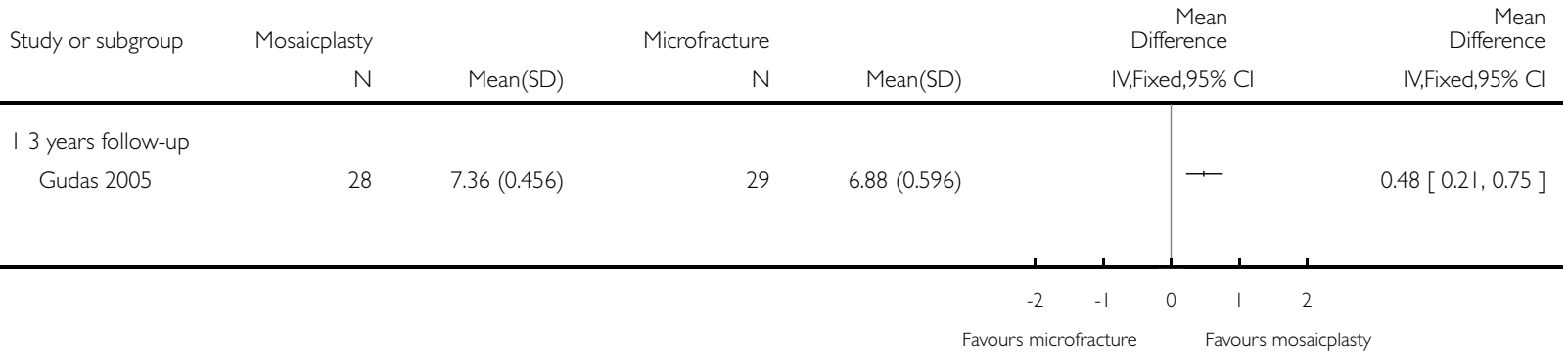

Analysis I.7. Comparison I Mosaicplasty versus microfracture, Outcome 7 Activity (Tegner score; I to I0: best score): long term (5 or more years follow-up).

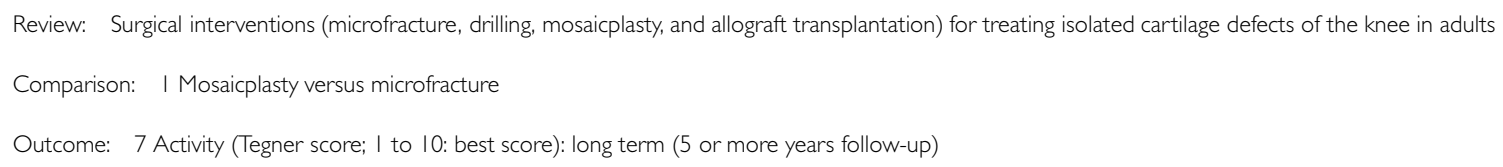

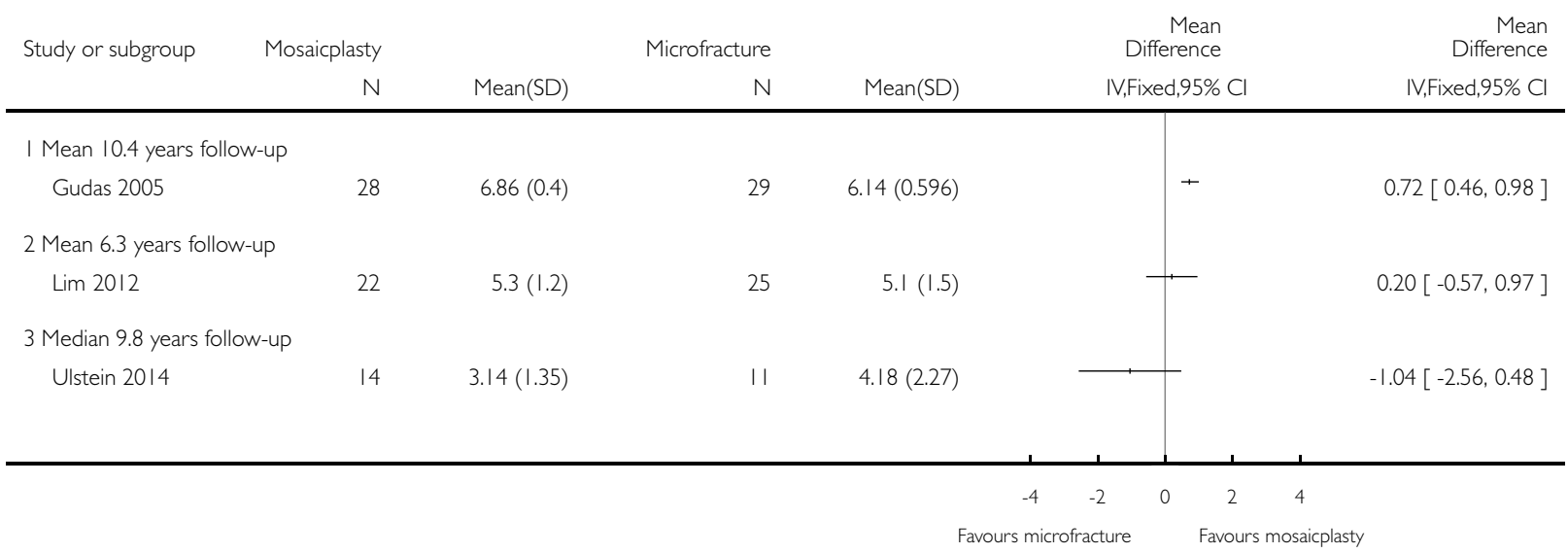




\section{Analysis I.8. Comparison I Mosaicplasty versus microfracture, Outcome 8 Sports activity.}

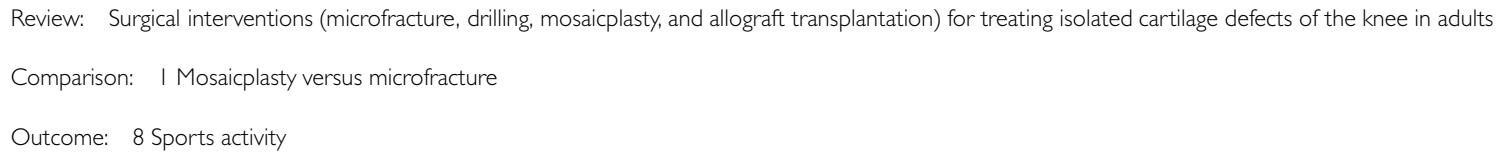

2 Continuation of sports at 3 years

Gudas 2005

15/29

$8 / 29$

3 Continuation of sports at 10 years Gudas 2005 $n / N$

$+$

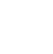

$1.80[1.24,2.59]$

$3.24[1.77,5.92]$

$2.07[0.81,5.30]$

(I) Mean return at 6.5 months after surgery 


\section{Analysis I.9. Comparison I Mosaicplasty versus microfracture, Outcome 9 Quality of cartilage at long-term follow-up: magnetic resonance image (satisfactory cartilage characteristics).}

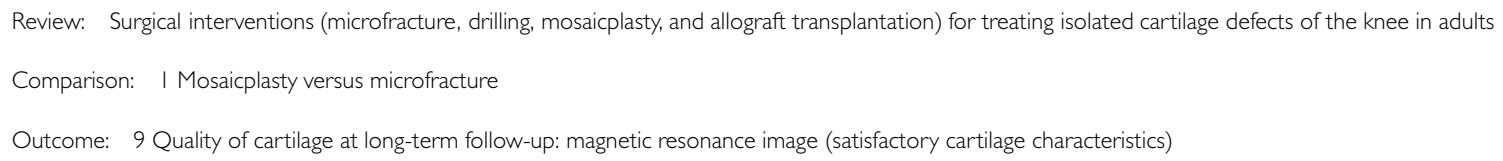

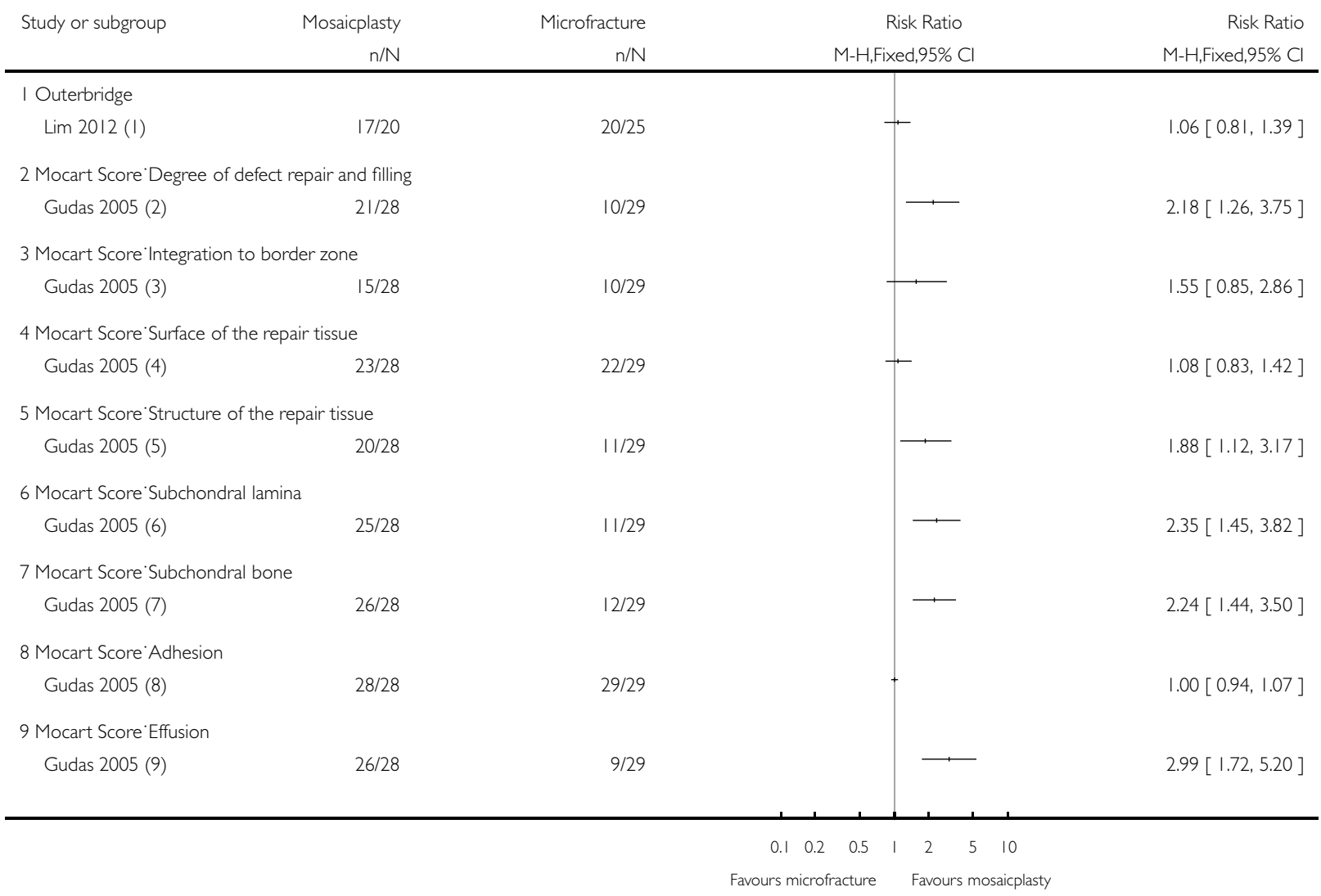

(I) Outerbridge grade I and 2

(2) Complete - Mocart

(3) Complete - Mocart

(4) Intact-Mocart

(5) Homogeneous - Mocart

(6) Intact - Mocart

(7) Intact - Mocart

(8) No adhesion - Mocart

(9) No effusion - Mocart 
Analysis I.10. Comparison I Mosaicplasty versus microfracture, Outcome 10 Quality of cartilage: "Secondlook" arthroscopy at around I year. Excellent and good.

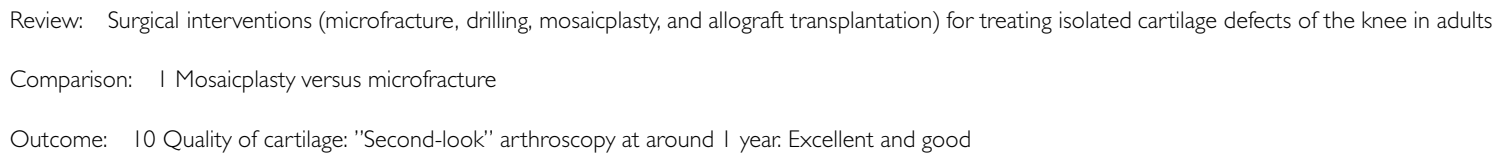

$9 / 20$

\begin{tabular}{ll}
$\mathrm{Cl}$ & $\mathrm{Cl}$ \\
\cline { 2 - 2 } &
\end{tabular}

Total events: 25 (Mosaicplasty), 25 (Microfracture)

Heterogeneity: $\mathrm{Tau}^{2}=0.11 ; \mathrm{Chi}^{2}=3.01, \mathrm{df}=\mathrm{I}(\mathrm{P}=0.08) ; \mathrm{I}^{2}=67 \%$

Test for overall effect: $Z=0.89(P=0.37)$

Test for subgroup differences: Not applicable

$\left.\begin{array}{ll|lll} & & & 100.0 \% & 1.28[0.74,2.21\end{array}\right]$

( I) ICRS grade I and 2

(2) ICRS grade I and 2

\section{Analysis I.I I. Comparison I Mosaicplasty versus microfracture, Outcome II Quality of cartilage: presence of hyaline cartilage in biopsy.

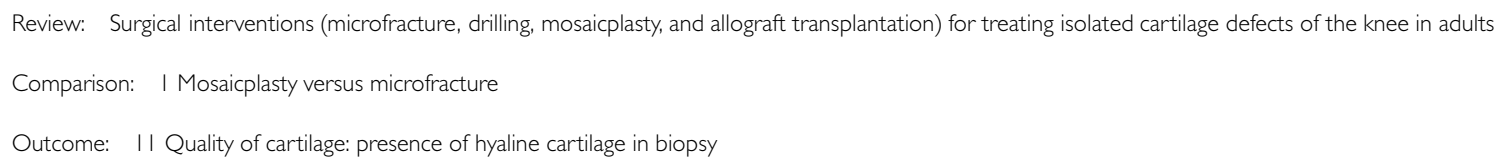

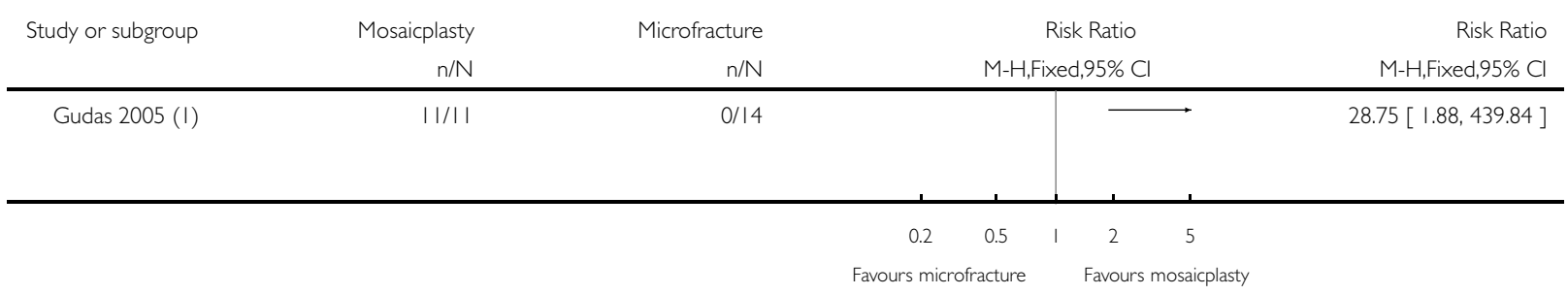

( I) Presence of hialine cartilage

Surgical interventions (microfracture, drilling, mosaicplasty, and allograft transplantation) for treating isolated cartilage defects of the knee in adults (Review)

Copyright $\Subset 2016$ The Cochrane Collaboration. Published by John Wiley \& Sons, Ltd. 


\section{Analysis I.12. Comparison I Mosaicplasty versus microfracture, Outcome 12 Quality of cartilage at long} term follow-up: signs of radiographic osteoarthritis.

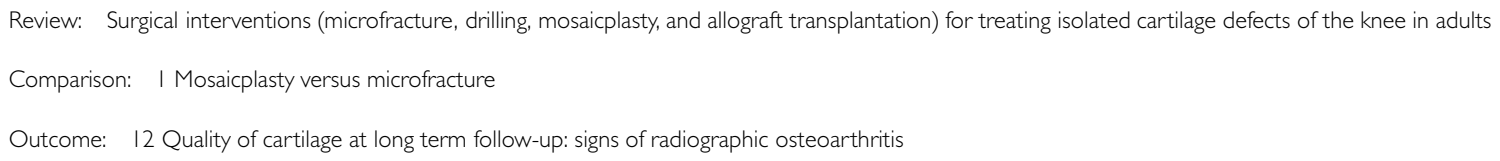

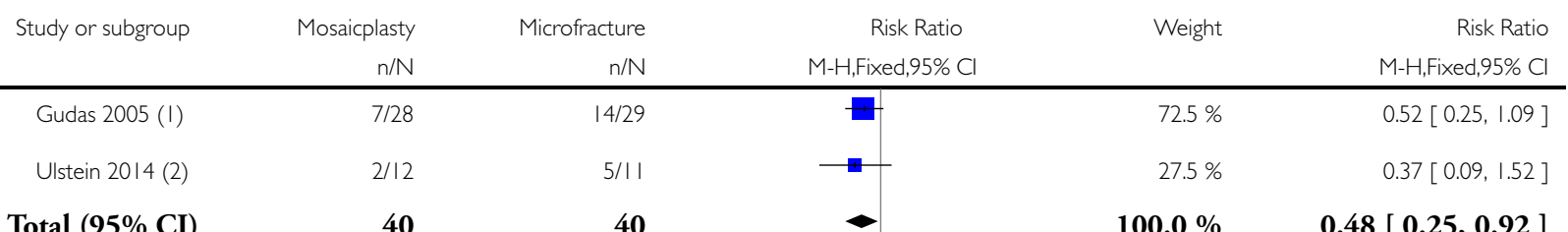

Total events: 9 (Mosaicplasty), 19 (Microfracture)

(I) Kellgren-Lawrence grade I; mean follow-up 10.4 years

(2) kellgren-Lawrence grade 2 or more; median follow-up 9.8 years

\section{ADDITIONAL TABLES}

Table 1. Key baseline characteristics of the included trials

\begin{tabular}{|c|c|c|c|c|c|c|c|c|}
\hline Study ID & $\begin{array}{l}\text { Number } \\
\text { with } \\
\text { baseline } \\
\text { data }\end{array}$ & $\begin{array}{l}\text { Mean age in } \\
\text { years }\end{array}$ & Males (\%) & Sports & $\begin{array}{l}\text { Defect } \\
\text { grade }\end{array}$ & $\begin{array}{l}\text { Defect } \\
a \text { area range } \\
\text { and mean in } \\
\mathrm{cm}^{2}\end{array}$ & $\begin{array}{l}\text { Trauma ori- } \\
\text { gin }(\%)\end{array}$ & $\begin{array}{l}\text { Mean dura- } \\
\text { tion } \\
\text { of } \\
\text { symptoms } \\
\text { in months }\end{array}$ \\
\hline Gudas 2005 & 57 & 24.4 & $36(63)$ & All athletes & $\begin{array}{l}\text { ICRS } \\
3 \text { or } 4^{b}\end{array}$ & $\begin{array}{l}1.0 \text { to } 4.0^{b} \\
\text { mean } 2.78\end{array}$ & $32(56)$ & 21.3 \\
\hline $\operatorname{Lim} 2012$ & $51^{c}$ & 31.8 & $29(57)$ & ? & $\begin{array}{l}\text { Outerbridge } \\
3 \text { or } 4^{b}\end{array}$ & $\begin{array}{l}1.0 \text { to } 4.0 \\
\text { mean } 2.76\end{array}$ & $?^{d}$ & ? \\
\hline $\begin{array}{l}\text { Ulstein } \\
2014\end{array}$ & 25 & 32.3 & $14(56)$ & $\begin{array}{l}\text { All with Teg- } \\
\text { ner score }<6 \\
b\end{array}$ & $\begin{array}{l}\text { ICRS } \\
3 \text { or } 4^{b}\end{array}$ & $\begin{array}{l}2.0 \text { to } 6.0 \\
\text { mean } 2.82\end{array}$ & $11(44)$ & 91.3 \\
\hline $\begin{array}{l}a \text { all were sing } \\
b \text { inclusion cri } \\
{ }^{c} 52 \text { knees } \\
{ }^{d} \text { isolated lesio }\end{array}$ & $\begin{array}{l}\text { e lesions } \\
\text { erion } \\
\text { n, no othe }\end{array}$ & injuries & & & & & & \\
\hline
\end{tabular}

Surgical interventions (microfracture, drilling, mosaicplasty, and allograft transplantation) for treating isolated cartilage defects of the 
ICRS: International Cartilage Repair Society score

\section{A P P E N D I C ES}

\section{Appendix I. International Cartilage Repair Society classification}

The ICRS classifies osteochondral lesions by arthroscopic view based on the depth of the injury; lesions are graded from 0 to 4 , as detailed below:

ICRS-0: Normal cartilage.

ICRS-1a: Fibrillation and/or slight softening; ICRS-1b: Superficial lacerations and fissures.

ICRS-2: Defects that involve less than $50 \%$ of the cartilage thickness.

ICRS-3: Defects that involve more than $50 \%$ of the cartilage thickness but not the subchondral bone.

ICRS-4: Defects that involve subchondral bone

\section{Appendix 2. Search strategies}

\section{CENTRAL (Wiley Online Library)}

\#1 MeSH descriptor: [Cartilage] this term only (88)

\#2 MeSH descriptor: [Hyaline Cartilage] this term only (5)

\#3 MeSH descriptor: [Cartilage, Articular] this term only (265)

\#4 MeSH descriptor: [Fractures, Cartilage] this term only (28)

\#5 cartilage:ti,ab (976)

\#6 (osteochondral or chondral):ti,ab (140)

\#7 chondroplasty:ti,ab (14)

$\# 8 \# 1$ or \#2 or \#3 or \#4 or \#5 or \#6 or \#7 (1177)

\#9 MeSH descriptor: [Knee] this term only (642)

\#10 MeSH descriptor: [Knee Joint] this term only (2533)

\#11 MeSH descriptor: [Knee Injuries] this term only (713)

\#12 MeSH descriptor: [Patella] this term only and with qualifier(s): [Injuries - IN] (22)

\#13 ((medial or lateral) near condyle*):ti,ab,kw (Word variations have been searched) (80)

\#14 trochlea*:ti,ab (30)

\#15 patella*:ti,ab (999)

\#16 knee*:ti,ab (12763)

$\# 17 \# 9$ or \#10 or \#11 or \#12 or \#13 or \#14 or \#15 or \#16 (13582)

\#18 \#8 and \#17 (631)

\#19 MeSH descriptor: [Bone Transplantation] this term only (792)

\#20 MeSH descriptor: [Transplantation, Homologous] this term only (1287)

\#21 (allograft* or homograft* or allotransplant* or ((allogenic or allogeneic or homologous or homoplastic or homogenous) near/3 (graft* or homograft*))):ti,ab (2493)

\#22 microfractur*:ti,ab (86)

\#23 (pridie or drill* or microdrill*):ti,ab (539)

\#24 abrasion:ti,ab (352)

\#25 MeSH descriptor: [Transplantation, Autologous] this term only (1507)

\#26 mosaicplasty:ti,ab (20)

\#27 ((osteochondral or mosaic*) near/3 (autologous or autogenous or autograft)):ti,ab (20)

Surgical interventions (microfracture, drilling, mosaicplasty, and allograft transplantation) for treating isolated cartilage defects of the 
$\# 28 \# 19$ or \#20 or \#21 or \#22 or \#23 or \#24 or \#25 or \#26 or \#27 (6036)

\#29 \#18 and \#28 (78) [Trials]

\section{MEDLINE (Ovid Online)}

1 Cartilage/ or Hyaline Cartilage/ or Cartilage, Articular/ or Fractures, Cartilage/ (47067)

2 cartilage.ti,ab. (64546)

3 (osteochondral or chondral).ti,ab. (6373)

4 chondroplasty.ti,ab. (175)

5 or/1-4 (81699)

6 Knee/ (11982)

7 Knee Joint/ (42791)

8 Knee Injuries/ (15931)

9 Patella/in [Injuries] (1972)

10 ((medial or lateral) adj condyle*).tw. (1082)

11 trochlea*.ti,ab. (2824)

12 patella*.ti,ab. (15647)

13 knee*.ti,ab. (104722)

14 or/6-13 (130159)

15 and/5,14 (14929)

16 Bone Transplantation/ (26845)

17 Transplantation, Homologous/ (76800)

18 (allograft* or homograft* or allotransplant* or ((allogenic or allogeneic or homologous or homoplastic or homogenous) adj3 (graft* or homograft*))).tw. (65864)

19 microfractur*.tw. (1169)

20 (pridie or drill* or microdrill*).tw. (12791)

21 abrasion.tw. (5480)

22 Transplantation, Autologous/ (44650)

23 mosaicplasty.tw. (226)

24 ((osteochondral or mosaic*) adj3 (autologous or autogenous or autograft)).ti,ab. (594)

25 or/16-24 (189974)

26 Randomized controlled trial.pt. (405016)

27 Controlled clinical trial.pt. (90022)

28 randomized.ab. (334096)

29 placebo.ab. (165753)

30 Drug therapy.fs. (1813051)

31 randomly.ab. (241205)

32 trial.ab. (345097)

33 groups.ab. (1510010)

34 or/26-33 (3643412)

35 exp Animals/ not Humans/ (4177405)

3634 not 35 (3132983)

37 and/15,25,36 (280)

\section{EMBASE (Ovid Online)}

1 Cartilaginous Tissue/ or Articular Cartilage/ or Hyaline Cartilage/ or Cartilage Injury/ or Cartilage/ or exp Cartilage Transplantation/ or Articular Cartilage/ or Cartilage Fracture/ or Cartilage Cell/ (74043)

2 cartilage.ti,ab. (75916)

3 (osteochondral or chondral).ti,ab. (7569)

4 chondroplasty.ti,ab. (209)

5 or/1-4 (105149)

6 Knee/ (49464)

Surgical interventions (microfracture, drilling, mosaicplasty, and allograft transplantation) for treating isolated cartilage defects of the 
7 Knee surgery/ (4154)

8 Knee injury/ (11696)

9 Patella/su [Surgery] (791)

10 ((medial or lateral) adj condyle*).tw. (1251)

11 trochlea*.ti,ab. (3236)

12 patella*.ti,ab. (17754)

13 knee*.ti,ab. (130178)

14 or/6-13 (152572)

15 and/5,14 (19707)

16 exp Bone transplantation/ (40986)

17 Allotransplantation/ (32996)

18 (allograft* or homograft* or allotransplant* or ((allogenic or allogeneic or homologous or homoplastic or homogenous) adj3 (graft* or homograft*))).tw. $(82441)$

19 microfractur*.tw. (1453)

20 (pridie or drill* or microdrill*).tw. (14672)

21 abrasion.tw. (5921)

22 Transplantation, Autologous/ (25692)

23 mosaicplasty.tw. (264)

24 ((osteochondral or mosaic*) adj3 (autologous or autogenous or autograft)).ti,ab. (700)

25 or/16-24 (182301)

26 Randomized controlled trial/ (391260)

27 Clinical trial/ (852425)

28 Controlled clinical trial/ (391679)

29 Randomization/ (69116)

30 Single blind procedure/ (21397)

31 Double blind procedure/ (125755)

32 Crossover procedure/ (45858)

33 Placebo/ (269531)

34 Prospective study/ (319564)

35 ((clinical or controlled or comparative or placebo or prospective* or randomi\#ed) adj3 (trial or study)).tw. (883126)

36 (random* adj7 (allocat* or allot* or assign* or basis* or divid* or order*)).tw. (217517)

37 ((singl* or doubl* or trebl* or tripl*) adj7 (blind* or mask*)).tw. (180569)

38 (cross?over* or (cross adj1 over*)).tw. (77930)

39 ((allocat* or allot* or assign* or divid*) adj3 (condition* or experiment* or intervention* or treatment* or therap* or control* ${ }^{*}{ }^{*}$ group*)).tw. (290019)

40 RCT.tw. (19278)

41 or/26-40 (2144429)

42 Case Study/ or Abstract Report/ or Letter/ (983271)

4341 not 42 (2103087)

4415 and 25 and $43(506)$

\section{SPORTDiscus (EBSCOhost)}

S1 (DE “ARTICULAR cartilage”) OR (DE “CARTILAGE” OR DE “CARTILAGE -- Wounds \& injuries” OR DE “CARTILAGE cells") $(2,536)$

S2 TI cartilag* OR AB cartilag* $(3,626)$

S3 TI ( (osteochondral or chondral) ) OR AB ( (osteochondral or chondral) ) $(1,392)$

S4 TI chondroplasty OR AB chondroplasty (54)

S5 S1 OR S2 OR S3 OR S4 $(4,874)$

S6 DE “KNEE” (10,714)

S7 DE “KNEE -- Wounds \& injuries" $(1,650)$

S8 DE “KNEE -- Surgery” (0)

S9 DE "PATELLA -- Wounds \& injuries" (72)

Surgical interventions (microfracture, drilling, mosaicplasty, and allograft transplantation) for treating isolated cartilage defects of the 
S10 ((medial or lateral) n3 condyle*) (532)

S11 TI trochlea* OR AB trochlea* (342)

S12 TI patella* OR AB patella* $(4,069)$

S13 TI knee* OR AB knee* $(32,144)$

S14 S6 OR S7 OR S8 OR S9 OR S10 OR S11 OR S12 OR S13 $(36,654)$

S15 DE "BONE-grafting" (736)

S16 DE "HOMOGRAFTS" (885)

S17 TX (allograft* or homograft* or allotransplant* or ((allogenic or allogeneic or homologous or homoplastic or homogenous) n3 (graft* or homograft*))) $(1,447)$

S18 DE "MICROFRACTURE surgery" (82)

S19 TX microfractur* (314)

S20 TX (pridie or drill* or microdrill*) $(11,082)$

S21 TX abrasion (395)

S22 DE “AUTOGRAFTS” (544)

S23 TX mosaicplasty (78)

S24 TI ( ((osteochondral or mosaic*) n3 (autologous or autogenous or autograft)) ) OR AB ( ((osteochondral or mosaic*) n3 (autologous or autogenous or autograft)) ) (206)

S25 S15 OR S16 OR S17 OR S18 OR S19 OR S20 OR S21 OR S22 OR S23 OR S24 $(14,091)$

S26 S5 AND S14 AND S25 (537)

S27 TX ( (clinic* N3 trial) or (controlled N3 trial) or (comparative N3 trial) or (placebo N3 trial) or (prospective N3 trial) or (randomi? ed N3 trial) ) or TX ( (clinic* N3 study) or (controlled N3 study) or (comparative N3 study) or (placebo N3 study) or (prospective N3 study) or (randomi?ed N3 study) ) $(68,688)$

S28 (random* N7 allot*) or (random* N7 assign*) or (random* N7 basis*) or (random* N7 divid*) or (random* N7 order*) $(9,229)$

S29 TX ( (singl* N7 blind*) or (doubl* N7 blind*) or (trebl* N7 blind $\left.{ }^{*}\right)$ or (tripl* N7 blind $\left.{ }^{*}\right)$ ) or TX ( (singl* N7 mask*) or (doubl*

N7 mask*) or (trebl* N7 mask*) or (tripl* N7 mask*) ) (5,763)

S30 TX (cross\# over $\left.^{*}\right)$ or TX (cross N1 over*) $(4,434)$

S31 TX randomi?ed control* trial $^{*}(10,669)$

S32 TX ( (allocat* N3 condition*) or (allocat* N3 experiment*) or (allocat* N3 intervention*) or (allocat* N3 treatment*) or (allocat* N3 therap ${ }^{*}$ ) or (allocat* N3 control*) or (allocat* N3 group*) ) or TX ( (allot* N3 condition*) or (allot* N3 experiment*) or (allot* N3 intervention*) or (allot* N3 treatment*) or (allot* N3 therap*) or (allot* N3 control*) or (allot* N3 group*) ) or TX ( (assign* N3 condition ${ }^{*}$ ) or (assign* N3 experiment*) or (assign* N3 intervention*) or (assign* N3 treatment*) or (assign* N3 therap*) or (assign* N3 control*) or (assign* N3 group*) ) or TX ( (divid* N3 condition*) or (divid* N3 experiment*) or (divid* N3 intervention*) or (divid* N3 treatment*) or (divid* N3 therap*) or (divid* N3 control*) or (divid* N3 group $\left.\left.{ }^{*}\right)\right)(10,207)$

S33 TX placebo* $(8,374)$

S34 S27 or S28 or S29 or S30 or S31 or S32 or S33 $(84,945)$

S35 S26 AND S34 (160)

S36 $(321,436)$

S37 S35 AND S36 (160)

\section{LILACS (BIREME IAHx interface)}

\#1: (MH:“Cartilage” OR MH:A10.165.382\$ OR MH:A02.165\$) OR (MH:"Hyaline Cartilage” OR MH:A02.165.407\$ OR MH:A10.165.382.400\$) OR (MH:"Fractures, Cartilage” OR MH:C26.411\$) OR (MH:"Knee” OR MH:A01.378.610.450\$) OR (MH:"Knee Injuries” OR MH:C26.558.554\$) OR (MH:"Knee Joint” OR MH:A02.835.583.475\$) OR (MH:"Patella” OR MH: A02.835.232.043.650.624\$)

AND

\#2:(MH:“Bone Transplantation” OR MH:E04.555.130\$ OR MH:E04.936.450.050\$) OR (MH:“Transplantation, Homologous” OR MH:E04.936.864\$) OR (MH:“Transplantation, Autologous” OR MH:E04.936.664\$) OR TW:microfractur\$ OR TW:drill\$ OR TW:mosaic\$

\#3: \#1 AND \#2 (214)

\section{ClinicalTrials.gov}

Surgical interventions (microfracture, drilling, mosaicplasty, and allograft transplantation) for treating isolated cartilage defects of the 
knee AND (cartilage OR chondral OR osteochondral) AND (transplantation OR microfracture OR drilling OR mosaicplasty OR allograft) (75)

\section{WHO ICTRP}

Advanced search option

Condition: Cartilage OR Chondral OR Osteochondral

Intervention: Transplantation OR Microfracture OR Drilling OR Mosaicplasty OR Allograft

Recruitment status is ALL (38)

\section{ISRCTN Registry}

Knee AND (Cartilage OR Chondral OR Osteochondral) AND (Transplantation OR Microfracture OR Drilling OR Mosaicplasty OR Allograft) (4)

\section{CONTRIBUTIONSOFAUTHORS}

All authors contributed to the review. GG, VM, CF, ML and JB drafted the review and all authors provided comments and approved the final version. The guarantor of this review is Guilherme Conforto Gracitelli.

\section{DECLARATIONSOF INTEREST}

Guilherme C. Gracitelli performs research in allograft transplantation at the Shiley Center For Orthopedic Research \& Education (La Jolla, USA) and at the Federal University of São Paulo (São Paulo, Brazil). No study on allograft transplantation was included in this review.

\section{SOURCES OF SUPPORT}

\section{Internal sources}

- Escola Paulista de Medicina - Universidade Federal de Sa ${ }^{\sim}$ o Paulo, Brazil. Academic and technical support.

\section{External sources}

- No sources of support supplied 


\section{DIFFERENCES BETWEEN PROTOCOLANDREVIEW}

When trials included more than one measure of function, we chose the IKDC score (included in the ICRS cartilage injury evaluation package but referred to as ICRS scores in Gudas 2005) and Lysholm score rather than HSS score and KOOS score. Lysholm is the most commonly used in the literature and the KOOS score has five subgroups that are not recommended to be summed.

We included two subcategories of the KOOS score, quality of life (KOOS QOL) and KOOS pain, as primary and secondary outcomes. We also included the categorisation of activity level from the ICRS 'Cartilage Injury Standard Evaluation Form'.

Our previously defined subgroup analyses were not performed because of lack of data. We introduced a modified subgroup analysis (cartilage defect (chondral lesion) versus osteochondral defect (osteochondral lesion)). We opted to introduce this subgroup because osteochondral lesions require treatment of not only the cartilage but the damaged bone (Gomoll 2010a). Surgical treatment options such as mosaicplasty and allograft transplantation have the theoretical advantage of treating bone and cartilage defects at the same time and could potentially present better clinical outcomes than microfracture and drilling. Based on that, some algorithms of treatment available in the literature base their surgical decision on whether bone damage is present.

We decided to present a 'Summary of findings' table in order to highlight the insufficiency of the data as well as to give a better view of clinical relevance of the results. We selected for presentation all three primary outcomes, with pain and activity level assessed via the Tegner score; for both function and activity levels, we presented separate results for intermediate- and long-term follow-up. 